\title{
A DEA model for measuring financial intermediation
}

\author{
Martin Bod'a ${ }^{1,2}$ - Emília Zimková1 [ \\ Received: 8 December 2019 / Accepted: 11 May 2020 / Published online: 3 June 2020 \\ ๑) Springer Science+Business Media, LLC, part of Springer Nature 2020
}

\begin{abstract}
It is common practice in data envelopment analysis to assess commercial banks by the efficiency that they display in their operations under different outlooks on their behaviour; yet, even the intermediation approach does not measure actually the success with which commercial banks or a banking sector fulfil their mission of financial intermediaries. Such an assessment is traditionally accomplished by means of the loan-to-deposit ratio that captures rather size or depth of financial intermediation, but no link is sought to best practices that are observed in the banking sector. The paper proposes a model of financial intermediation that permits assessing on a comparative basis the attainment in financial intermediation. The devised index of financial intermediation recognizes through weights that diverse outcomes of financial intermediation exhibit differentiated importance to the economy and is closely connected with the weighted slacks-based measure (WSBM). The WSBM that emerges in this respect encompasses only production variables that define financial intermediation (i.e. deposits and intermediated outputs) whilst other production variables are treated as non-discretionary. The model can be applied in variants for a single commercial bank in one specific year (Model I) or for aggregated bankyears such as one particular bank over the entire period or various banks in one year (Model II). The ideas are demonstrated on a data set of Slovak commercial banks for the period between 2008 and 2016 and the difference of the proposed approach with traditional efficiency measurement under the intermediation approach is discussed.
\end{abstract}

Keywords Financial intermediation · Loan-to-deposit ratio $\cdot$ Data envelopment analysis $($ DEA $) \cdot$ Weighted slacks-based measure $(\mathrm{WSBM}) \cdot$ Aggregation over years or banks

\section{JEL Classification G20 · E59 · O50}

\author{
Martin Boda \\ martin.boda@outlook.com \\ Emília Zimková \\ emilia.zimkova@umb.sk
}

1 Faculty of Economics, Matej Bel University in Banská Bystrica, Tajovského 10, 97590 Banská Bystrica, Slovakia

2 Faculty of Natural Sciences, Jan Evangelista Purkyně University in Ústí nad Labem, České mládeže 8, 40096 Ústí nad Labem, Czech Republic 


\section{Introduction}

The financial sector serves an economy with manifold functions, out of which financial intermediation is perhaps the most important service as it is contributive to economic growth and prosperity (Thiel 2001, p. 7). Financial intermediation consists in connecting surplus units (investors that are in an excess of available funds) to deficit units (debtors that are in a shortage of funds) and secures that economic activities that lack financial funds do obtain their funding. This is the role that is highlighted in elementary treatments of financial markets and institutions (e.g. Saunders and Cornett 2009, p. 13; Madura 2003, pp. 14-15) and further explored in advanced expositions (see Freixas and Rochet 2008, pp. 15-67; Matthews and Thompson 2005; pp. 33-50). The considerations expended in this regard are merely to study benefits of financial intermediation (size, maturity and risk transformation of intermediated funds, delegated monitoring and others), and the existing models based on macroeconomic theory are put to use to demonstrate that the ultimate effect is moderation of transaction costs for both surplus and deficit units. In spite of the declared benefits of financial intermediation and models proving its uniqueness for economic growth, what is overlooked and insufficiently recognized is that financial intermediation must be accomplished and this accomplishment may be far from being optimal. From a macroeconomic point of view, financial intermediation is successful when effective demand for funds is satisfied with available funds collected from surplus units. Of course, there are different types of financial intermediaries. Some collect funds from surplus units in the form of deposits and distribute them to deficit units in the form of loans, others are engaged with their operations more with the capital market and lend via the purchase of securities. The present text concentrates on the former category that includes banks and other depository institutions. In banking practice and regulation, the extent of financial intermediation is measured by the loan-to-deposit ratio that confronts for a bank or for the sector the amount of funds intermediated/loaned and the amounts of funds collected/deposited (Office of the Comptroller of the Currency 2016; European Banking Authority 2017, p. 37). Nonetheless, such a ratio indicator is merely a positive indicator of accomplishment in financial intermediation and not a normative one since it fails to indicate whether financial intermediation could not have been better. It merely describes size or depth of financial intermediation as was rendered with no reference to best practices.

With a focus laid upon the banking provision of financial intermediation, the present paper strives to rectify this perceptible deficiency of the traditional assessment based on a single ratio. For the needs of macroeconomic policy and also in part of banking regulation, the paper proposes a model of financial intermediation that builds from the principles of data envelopment analysis (DEA) and that is designated to identify and measure lost opportunities in financial intermediation. These lost opportunities present themselves whenever there is a missed chance of transforming a smaller volume of available funds (deposits) into a greater volume of intermediated funds (loans). In spite of confining banking production notionally to taking on one common category of deposits (on the input side) in providing different categories of loans (on the output side), the utilization of the model is much 
broader as the list of different categories of loans may equally well encompass noncreditory outcomes of financial intermediation such as mutual fund shares and other securities. The modelling framework posits in general that there is a set of bank-year observations available that are used to identify the production possibility set in a conventional manner as a conical or convex hull of the observed data (or any other adequate specification of returns to scale). In the estimated production possibility set, the most convenient projection is sought with respect to the variables engaged directly in financial intermediation (i.e. deposits and loan variables), whereas other inputs and outputs are treated as non-discretionary. The difference between the best attainable projection and the actually observed position is translated into an index of financial intermediation with the aid of deflation and inflation factors (for deposits and loans, respectively).

A thick line must be drawn at this instance between the present framework and the theoretical construct known in banking performance studies and elsewhere as the "intermediation approach". The latter concept assigns to the bank the raison d'etre of a financial intermediary, and this is the stand it takes in measuring its efficiency. In the resulting efficiency score are distilled not only aspects of financial intermediation, but also aspects of utilization of resources and of production that appertain to other (non-intermediation) banking business. In contrast, the present framework is not concerned with efficiency of all (i.e. also non-intermediary) banking activities, but isolates and measures in the form of an index merely aspects of intermediation activities. Since the intermediation approach as such is immensely proliferated and popular, its theoretical account is furnished in this text only marginally, but is available with notes on its use in a DEA context in Ahn and Le (2014). Still, a comparison of the traditional efficiency measurement founded on the intermediation approach and the measurement of attained financial intermediation according to the proposed modelling framework is provided. This comparison is part of the empirical demonstration, in which the proposed model is applied to a data set of Slovak commercial banks for a 9-year period between 2008 and 2016.

There are no less than three outstanding features of the model. Since it turns out that the index devised to measure the attainment in financial intermediation reduces to the inverse of a weighted slacks-based measure (WSBM) using only the variables involved directly in financial intermediation, traditional devices can be easily adapted to handle the proposed modelling framework. Second, the model is considered in two variants to assess financial intermediation. Model I answers to the case of one bank-year (one bank in a single year), whereas Model II corresponds to the case of several bank-years at a time (typically one bank over the entire period or the entire sector in one particular year). Third, the model recognizes that diverse categories of loans as outcomes of financial intermediation display basically differentiated significance to the economy and contribute to economic prosperity differently. This is captured through (most likely differentiated) weights assigned to different categories of loans; hence, the reason why the "weighted" SBM arises in the process.

The remainder of the paper is structured into four more sections. Whilst Sect. 2 makes short notes regarding financial intermediation, Sect. 3 describes the methodology for measuring the attainment in financial intermediation. Section 4 gives 
the empirical demonstration and is ensued by Sect. 5 that discusses and concludes. Some minor results are postponed to "Appendix".

\section{Financial intermediation and its modelling in the literature}

Financial intermediation aids an economy in resource allocation and transformation of financial contracts and securities understood in a loose meaning of the term (Freixas and Rochet 2008, p. 15). Primarily, financial intermediation mediates between users of funds (i.e. deficit spending units such as debtors) and providers of funds (i.e. surplus spending units such as investors or creditors). Secondarily, it secures asset transformation in terms of liquidity, quality and maturity, risk management, information processing, delegated monitoring of borrowers or brokerage services (Bhattacharya and Thakor 1993; Freixas and Rochet 2008, pp. 2, 15-18; Ahn and Le 2014, pp. 7-9). A number of microeconomic models have been developed in order to provide rationale for financial intermediation and to prove its benefits to an economy (see, for example, Freixas and Rochet 2008). These models study how financial intermediation influences the economy under a variety of market conditions and how government policies affect financial intermediation. Unfortunately, they fail to address the issue as to whether financial intermediaries are in their functions and activities good or feeble. Another research front, which suffers from the same limitations depicted above, is empirical, and this seeks to justify dependence of economic growth and prosperity upon financial development, which has come to be known as the finance-growth nexus. A large body of literature has represented financial intermediation by sundry partial indicators related to the financial sector (or institutions) without measuring whether financial intermediation in itself is successful at all (e.g. Hondroyiannis et al. 2005; Sharma and Bardhan 2017; Ho and Iyke 2018; Olaniyi and Oladeji 2020).

To some extent the matter of measuring attainment (or excellence) in financial intermediation is handled through the loan-to-deposit ratio, an indicator that is used in studies of a macroeconomic focus. This indicator is not appreciated sufficiently by the academic community, but is standard in regulatory use by central banks (Office of the Comptroller of the Currency 2016; DiSalvo and Johnston 2017; European Banking Authority 2017, p. 37). One of possible interpretations of the loan-to-deposit ratio is that it is a comprehensive measure of attainment in financial intermediation by commercial banks that collect funds in the form of deposits and grant them in the form of loans. Apparently, its descriptive role is more pronounced in financial systems where institutionalized capital markets play a minor role. Although the loan-to-deposit ratio is easily computable and interpretable, it suffers from all deficiencies that befall traditional ratio analysis (see Paradi and Zhu 2013 , pp. 62-63, and the references therein). Furthermore, it is a static measure that captures the relationship between the balance sheet amounts of total deposits and total loans and does not inform whether this proportion might not be more advantageous or to what extent the intermediation potential of banks was utilized in order to create a maximum of loans possibly with a minimum of deposits. 
In spite of a misleading similarity, excellence in financial intermediation per se differs conceptually from efficiency in banking operations as is outlined under the "intermediation approach" irrespective of whether it efficiency is examined using DEA or a stochastic frontier approach. The model proposed in this paper zooms in upon how a bank fares in collecting deposits and dispersing them in the form of loans, whilst the intermediation approach as viewed in efficiency studies centres upon efficiency of (all) banking operations when the bank is predestined as a financial intermediary (rather than a facility producing banking services). The intermediation approach is in detail described, for example, in Ahn and Le (2014, pp. 9-12) and Duygun-Fethi and Pasiouras (2010, p. 191). Adoption of the intermediation approach first and foremost translates into a specification of the model of banking production in which deposits are identified as (one of the) inputs and loans as outputs. Also the present model requires that a production model be postulated and then explores to what extent loans can be expanded and deposits contracted so that a production remains feasible. Furthermore, the sole focus the proposed modelling framework to loans and deposits ameliorates the issue with the intermediation approach observed by Fortin and Leclerc (2007) who find that an incomplete coverage of intermediated assets and liabilities in the specified input-output set produces bias in technical efficiency measurement. In fact, deliberate specialization to loans and deposits in measuring attainment in financial intermediation neglects other assets and liabilities that may be instrumental in intermediation activities (and leads to an incomplete coverage of the balance sheet), but also highlights what both academic and practitioners' community finds the core of financial intermediation carried out by commercial banks - transformation of deposits into loans.

To the best knowledge of the authors, no other methodological framework is proliferated that serves the purpose of measuring attainment in financial intermediation than the one grounded in using the loan-to-deposit ratio. Unfortunately, as explained afore, the loan-to-deposit ratio is not actually an indicator depicting success in financial intermediation. A first attempt to measure financial intermediation is the model proposed by Bod'a and Zimková (2018). Yet, it is a rudimentary model. It may be footed upon DEA ideas, but it strives to maximize in a rather mechanical way the discrepancy between loans and deposits in order to establish a feasible projection upon the efficient frontier. This deviation is defined in an additive fashion as a difference.

\section{Proposed modelling framework}

A somewhat simplified approach to modelling the essence and structure of financial intermediation is posited that reduces the balance sheet of a commercial bank on the assets side into different kinds of loans and on the liabilities side into total deposits. Nonetheless, this simplistic view on financial intermediation has sound grounds and is defendable. Although commercial banks do employ also other funding in complement to total deposits, these purchased funds fulfil merely an accessory role and make up for slacks in deposits funding whenever traditional funds collected from 
depositors are not sufficient. Furthermore, in contrast to loans, it is scarcely useful to recognize different kinds of deposits as the decisively major portion of deposits comes from individual non-institutionalized depositors and not from business entities or banks. From a macroeconomic viewpoint, it is desirable to categorize loans by their target markets (and recognize, for example, corporate loans, personal loans and other loans) rather than to classify them by their maturity. Other criteria of grouping such as profit margin or riskiness may be of import to a bank, but are immaterial whenever the measurement of financial intermediation is undertaken on a macroeconomic or regulatory level. The reason being, various kinds of loans contribute to economic growth with varying degrees of relevance (see, for example, Choudhry 2012, pp. 59-74; Černohorský 2017; Malikov et al. 2015). Naturally, loans are not the only outcome of financial intermediation as banks also transform deposits into securities or other investments, but the avenue to generalization in this direction is obvious.

The following set-up thus assumes that there is a panel of observations available for $N$ banks over $T$ time periods $\left\{t_{1}, \ldots, t_{T}\right\}$. This panel may possibly be unbalanced, but for an arbitrary bank $i$ (where $i \in\{1, \ldots, N\}$ ) there are $T_{i} \geq 1$ observations available for years $\left\{t_{(1)}, \ldots, t_{\left(T_{i}\right)}\right\}$ such that $\left\{t_{(1)}, \ldots, t_{\left(T_{i}\right)}\right\} \subset\left\{t_{1}, \ldots, t_{T}\right\}$. To preserve the validity of mathematical presentation, in what follows, summations over bank-years are further carried out with respect to the full index set $\mathfrak{J}^{F}=\left\{[i, t]: i \in\{1, \ldots, N\}, t \in\left\{t_{(1)}, \ldots, t_{\left(T_{i}\right)}\right\}\right\}$. Each bank $i$ in an observed period $t$ transmutes deposits $D_{i t}$ into loans of different $\Omega$ categories, $L_{i t}^{1}, \ldots, L_{i t}^{\Omega}$ (with $\Omega \geq 1$ ). In banking production that underlies financial intermediation, deposits represent inputs and loans constitute outputs; yet, the process may be served by utilization or consumption of other $P$ inputs (in addition to deposits) and production of $R$ other desirable outputs (others than loans), which are further considered in vectorized form and denoted by $\mathbf{x}_{i t}=\left(x_{i t}^{1}, \ldots, x_{i t}^{P}\right)^{\prime}$ and $\mathbf{y}_{i t}=\left(y_{i t}^{1}, \ldots, y_{i t}^{R}\right)^{\prime}$. Whenever $P=0$ or $R=0$, these other inputs or outputs can simply be dropped and do not enter the formulations to come.

The conceptual interpretation of this situation is visualized in Fig. 1 that shows the circumstances of production and financial intermediation for a bank $i$ in a period $t$. Banking production converts a total of $1+P$ inputs $\left[D_{i t}, \mathbf{x}_{i t}\right]$ into a total of $\Omega+R$ outputs $\left[L_{i t}^{1}, \ldots, L_{i t}^{\Omega}, \mathbf{y}_{i t}\right]$. Whilst all inputs are most likely interconnected in production of all outputs as is indicated by the arrows, the visualization recognizes that the process of banking production consists of two different sub-processes: the transmutation of deposits into loans is the core of financial intermediation, and this transmutation is technically complemented by another sub-process in which typically other inputs are utilized (such as physical capital and labour force) in producing other outputs (such as various services rendered). Of course, the technical sub-process is effected alongside the intermediation sub-process and participates in it.

There are two key economic ingredients that the proposed framework necessitates: (1) technological invariance and (2) shared non-exhaustible demand for loans. First, in what follows, production data available for different years of the full $T$-year period and for various banks are pooled together, and the entire panel is utilized in constructing an estimate of the underlying production technology after the fashion of DEA. This is only possible by assuming hereinafter that the production technology 


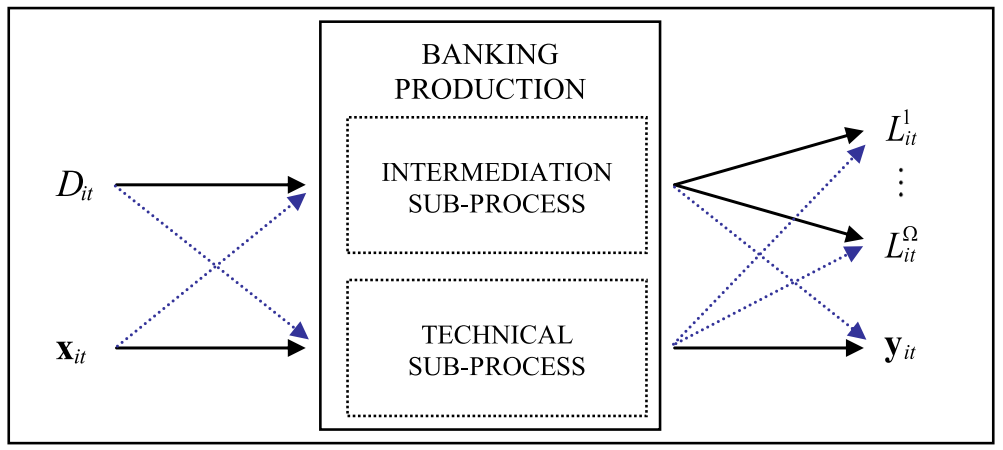

Fig. 1 Conceptual schema of banking production wherein financial intermediation is a sub-process

remains invariant and without alterations throughout the entire span of $T$ time periods. Naturally, this is barely an innocent assumption, but it is appropriate whenever there are no structural breaks, economic shifts or political upheavals. The decision which years can be deemed as free of structural breaks is obviously judgemental, albeit it may partly be assisted by analytical tools. The stringent assumption of technology invariance can be relaxed, which would necessitate some further adjustment and specialization of the ensuing formulations. Second, with a certain flavour of abstraction, it is also assumed that all banks face a non-exhaustible demand for loans of each type and so there are no limits on the volume of loans they may provide. The assumption is fairly strong since it entails that there are no serious competitive hindrances between banks and that no bank operates in markedly disadvantaged conditions. If this assumption were relaxed, the outcome is that the proposed approach would merely picture the attainment in financial intermediation in a pessimistic light and true attainment might be much more favourable.

A general idea of successful financial intermediation is that a maximum of loans is made at a minimum of deposits taken. Such a conception cannot be responsibly taken for flawless since certainly some level of deposits is healthy and inevitable. However, this can be handled by adding a suitable constraint upon total deposits as will be discussed later. Downward adjustments of deposits and upward adjustments of loans of different categories may be handled multiplicatively by individual radial adjustments or additively by slacks, and both these approaches are mathematically equivalent. In the initial portrayal of financial intermediation deposits are to be deflated whereas different categories of loans are to be inflated, which can be represented by simultaneous projections $D_{i t} \rightarrow \min \theta_{i t} D_{i t}\left(\right.$ where $\left.\theta_{i t} \leq 1\right)$ and $L_{i t}^{l} \rightarrow \max \psi_{i t}^{l} L_{i t}^{l}\left(\right.$ where $\left.\psi_{i t}^{l} \geq 1\right)$ for all $l \in\{1, \ldots, \Omega\}$. The factors $\theta_{i t}$ and $\psi_{i t}^{l}$ are traditional contraction and expansion adjustments of deposits and loans, respectively, which can be further restated through additive slacks in deposits $s_{D, i t}$ (excesses such that $s_{D, i t} \geq 0$ ) and in loans $s_{L, i t}^{l}$ (shortfalls such that $s_{L, i t}^{l} \geq 0$ ). Hence, the connection between the factors and slacks is governed by relationships $\theta_{i t}=1-s_{D, i t} / D_{i t}$ and $\psi_{i t}^{l}=1+s_{L, i t}^{l} / L_{i t}^{l}$. Whenever it is felt that deposits should not be suppressed beneath a pre-specified threshold, an extra constraint may be introduced such as $\theta^{-} \leq \theta_{i t}$, where $\theta^{-}$ 
is the maximum allowable contraction of deposits. The specification of $\theta^{-}$must be indispensably judgemental and may be uniform to all banks or vary according to the specific conditions of banks. It is further admitted that different categories of loans exhibit a differentiated effect upon smooth working of the economy and may have a differentiated bearing upon how financial intermediation is deemed. The differentiated importance of different types of loans is assumed to be embodied in normalized weights $v_{l}, l \in\{1, \ldots, \Omega\}$, such that $v_{l}>0$ for all $l \in\{1, \ldots, \Omega\}$ and $\sum_{l} v_{l}=1$.

Unrealized potential in financial intermediation can be naturally identified individually with different categories of loans and depicted by normalized inflation factors $\psi_{i t}^{l} / \theta_{i t}$ that can further be assembled into a weighted average representation $\sum_{l}\left(v_{l} \psi_{i t}^{l} / \theta_{i t}\right)$. The fundamental idea is that financial intermediation is successful and effective whenever all deposits are transmuted into loans, or possibly, with a minimum utilization of deposits maximum loans are provided. This suggests that deposits should be deflated to the greatest extent possible whereas loans should be inflated in like manner. In this context, a single ratio $\psi_{i t}^{l} / \theta_{i t}$ measures in an isolated way to what extent loans of type $l$ can be maximized relative to deposits that are wished to be jointly minimized. Note that the expression for $\psi_{i t}^{l} / \theta_{i t}$ emerges in fact from simplification

$$
\frac{\psi_{i t}^{l} L_{i t}^{l} / \theta_{i t} D_{i t}}{L_{i t}^{l} / D_{i t}}=\frac{\psi_{i t}^{l}}{\theta_{i t}}
$$

in which the numerator $\psi_{i t}^{l} L_{i t}^{l} / \theta_{i t} D_{i t}$ represents the maximum attainable partial loan-to-deposit ratio for loans of type $l$ and the denominator $L_{i t}^{l} / D_{i t}$ is the actually observed loan-to-deposit ratio. Hence, the ratio $\psi_{i t}^{l} / \theta_{i t}$ represents a factor by which the actually observed loan-to-deposit ratio may be increased. The weighted normalized inflation factor $\sum_{l}\left(v_{l} \psi_{i t}^{l} / \theta_{i t}\right)$ reflects stratified significance of different categories of loans and constitutes merely an importance-weighted multiplier applied to the current observed loan-to-deposit ratio. The suggested interpretation of $\sum_{l}\left(v_{l} \psi_{i t}^{l} / \theta_{i t}\right)$ is that a value of 1 will imply that financial intermediation is accomplished at its maximum potential, but a value greater than 1 will indicate that there is some ex post identifiable room for improvement and squandered capacity to financially connect deficit and surplus economic agents. In order to identify the highest unrealized potential in financial intermediation, the average factor $\sum_{l}\left(v_{l} \psi_{i t}^{l} / \theta_{i t}\right)$ need be maximized. Nevertheless, by subsequent manipulation, it is obtained that

$$
\sum_{l=1}^{l=\Omega} v_{l} \frac{\psi_{i t}^{l}}{\theta_{i t}}=\frac{\sum_{l=1}^{l=\Omega} v_{l} \psi_{i t}^{l}}{\theta_{i t}}=\frac{\sum_{l=1}^{l=\Omega} v_{l}\left(1+s_{L, i t}^{l} / L_{i t}^{l}\right)}{1-s_{D, i t} / D_{i t}}=\frac{1+\sum_{l=1}^{l=\Omega} v_{l}\left(s_{L, i t}^{l} / L_{i t}^{l}\right)}{1-s_{D, i t} / D_{i t}},
$$

which is but the reciprocal of a weighted slacks-based measure (WSBM) defined by dint of one input $D_{i t}$ and $\Omega$ outputs $L_{i t}^{l}, l \in\{1, \ldots, \Omega\}$, with differentiated weights. In consequence, the identification of the most pronounced unrealized potential in financial intermediation can be performed in a traditional WSBM framework since 


$$
\max \sum_{l=1}^{l=\Omega} v_{l} \frac{\psi_{i t}^{l}}{\theta_{i t}} \Leftrightarrow \min \frac{1-s_{D, i t} / D_{i t}}{1+\sum_{l=1}^{l=\Omega} v_{l}\left(s_{L, i t}^{l} / L_{i t}^{l}\right)}
$$

The WSBM presented in (3) after the min operator does not encompass other inputs $\mathbf{x}_{i t}$ and outputs $\mathbf{y}_{i t}$ that are to be treated in a DEA framework as traditional non-discretionary inputs and outputs or exogenously fixed production variables in the terminology of Banker and Morey (1986) who were amongst the first to realize that some variables owing to their non-discretionary nature should not enter an efficiency measure directly. These variables will assist in setting-up (or rather estimation) of the underlying production set that is formed by all $1+P$ inputs (deposits plus other inputs) and $\Omega+R$ outputs (loans of different categories plus other outputs).

The representation of the weighted normalized inflation factor as the reciprocal of the corresponding WSBM is the key ingredient to the proposed model of financial intermediation. Two variants of the model are devised and presented. Whilst one variant (addressed as Model I) captures the attainment in financial intermediation of a single bank in one period, the other variant (referred to as Model II) renders this on an aggregate basis - aggregated either for several time periods (perhaps the entire period analysed) or for several banks (perhaps the entire sector). Whilst the first variant, Model I, answers the question of how well a bank in one particular period accomplished financial intermediation, the second variant, Model II, can be specialized to measuring the attainment in financial intermediation of a single bank over the entire period or of the entire sector in one particular year. Needless to say, whenever the WSBM associated with Model I or Model II is optimized at a value of one, this indicates that financial intermediation is performed at the most convenient attainment and management of resources. Conversely, a value lower than one indicates that some potential is missed. As a consequence, the benchmark values for the average normalized inflation factor are then one and a value greater than one. Apparently, the logic of this construction lends a possibility of referring the average normalized inflation factor to as the index of financial intermediation.

Albeit the models are presented as fractional programming problems, they can easily be transformed to equivalent linear programming problems using the algebra of the Charnes-Cooper transformation. ${ }^{1}$ Model I is formulated for bank $o$ (with $o \in\{1, \ldots, N\}$ ) at time $\tau$ (where $\tau \in\left\{t_{(1)}, \ldots, t_{\left(T_{o}\right)}\right\}$ ) and strives to identify the unrealized potential in financial intermediation on the basis of the following fractional program

\footnotetext{
${ }^{1}$ The transformation itself is skipped here since the model happens to be a variation of the WSBM model and a reiteration of the technique would add no novelty to Tone (2001, p. 500). Inasmuch as the Charnes-Cooper transformation is also obvious with other models to come and in order to conserve space, it is not presented here.
} 


$$
\min \rho_{o \tau}=\frac{1-s_{D, o \tau} / D_{o \tau}}{1+\sum_{l=1}^{l=\Omega} v_{l}\left(s_{L, o \tau}^{l} / L_{o \tau}^{l}\right)}
$$

subject to

$$
\begin{gathered}
\sum \sum_{[i, t] \in \mathfrak{I}^{F}} \lambda_{i t} D_{i t}=D_{o \tau}-s_{D, o \tau}, \\
\left.\sum \sum_{[i, t] \in \mathfrak{J}^{F}} \lambda_{i t} L_{i t}^{l}=L_{o \tau}^{l}+s_{L, o \tau}^{l} \quad \text { (for } \quad \forall l \in\{1, \ldots, \Omega\}\right), \\
\sum \sum_{[i, t] \in \mathfrak{\Im}^{F}} \lambda_{i t} \mathbf{x}_{i t} \leqslant \mathbf{x}_{o \tau}, \quad \sum \sum_{[i, t] \in \mathfrak{F}^{F}} \lambda_{i t} \mathbf{y}_{i t} \geqslant \mathbf{y}_{o \tau}, \\
s_{D, o \tau} \leqslant\left(1-\theta^{-}\right) D_{o \tau}, \\
s_{D, o \tau} \geqslant 0 \quad \text { and } \quad s_{L, o \tau}^{l} \geqslant 0 \quad(\text { for } \quad \forall l \in\{1, \ldots, \Omega\}), \\
\lambda_{i t} \geqslant 0 \quad\left(\text { for } \quad \forall[i, t] \in \mathfrak{J}^{F}\right) \quad\left(\text { and optionally } \quad \sum \sum_{[i, t] \in \mathfrak{\Im}^{F}} \lambda_{i t}=1\right) .
\end{gathered}
$$

The production possibility set is formed in a usual way as the conical or convex hull generated by observed production activities arising by assembling all inputs (deposits and other inputs) and all outputs (loans and other outputs), but the production variables (with the status "other") that are not participating directly in financial intermediation are handled as non-discretionary (or exogenously fixed). It is worthwhile noting that by the assumption of technology invariance phrased earlier the production possibility set is estimated using the full panel of all bank-year observations encompassed in $\mathfrak{J}^{F}$ to which the production data for bank $o$ at time $\tau$ are matched. It depends on whether the convexity restriction requiring that intensity variables sum to unity is enforced by the optional condition in (4f). The imposition of the optional unit sum condition should be guided by conventional wisdom and hinges upon the presumed degree of homogeneity of observed production activities and their operating setting. In addition, condition (4d) is a mere restatement of the requirement $\theta^{-} \leq \theta_{i t}$ that the deflation of deposits should not be unbounded, but regulated by the carefully chosen lower bound $\theta^{-}$. Obviously, this condition becomes null and redundant if $\theta^{-}$is set to zero. Throughout the production possibility set, a projection upon the part of the frontier (envelope) is sought with the aid of (4) that minimizes the WSBM $\rho_{o \tau}$ and equivalently maximizes the weighted average normalized inflation factor $\rho_{o \tau}^{-1}$. By the stipulation of (4a)-(4f), this projection is achievable according as there is a possibility to generate production activities in line with the axioms underlying a production model (see, for example, Banker et al. 1984, p. 1081). A crucial aspect of (4) is that the objective function is to be minimized so the deviation from the most technically favourable weighted average loan-to-deposit ratio is to be identified. 
For each bank and time instance, there are as many as $\Omega+2$ crucial variables in the optimal solution of Model I yielded by (the linearized version of) program (4) relevant from an economic standpoint: the optimal solution for the weighted average normalized inflation factor $\rho_{o \tau}^{*-1}$, the optimized values of slacks $s_{D, o \tau}^{*}$ for deposits and $s_{L, o \tau}^{l *}, l \in\{1, \ldots, \Omega\}$, for loans of different categories. Whereas $\rho_{o \tau}^{*-1}$ is a comprehensive indicator of the missed potential in financial intermediation, the slack variables then quantify by what amount deposits might have been smaller and loans greater in order to improve in financial intermediation.

Unlike Model I, Model II operates on an aggregate basis and is designed to explain the average performance of a bank over the entire period or the entire sector in 1 year in terms of financial intermediation. Nonetheless, the aggregation framework embedded in Model II can be easily and straightforwardly generalized to other cases such as when only a few periods and one bank or one period and a few banks are considered in measuring the (average) attainment in financial intermediation. Assume that the aggregation is undertaken with respect to a subset $\mathfrak{I}$ of the full index set $\mathfrak{J}^{F}$. If Model II is applied to measure financial intermediation for a bank $o$ in the entire period, then $\mathfrak{I}=\left\{[o, t]: t \in\left\{t_{(1)}, \ldots, t_{\left(T_{o}\right)}\right\}\right.$. Similarwise, if it is applied to the entire sector in one particular time $\tau$, then $\mathfrak{J}=\left\{[i, \tau]: i \in\{1, \ldots, N\},[i, \tau] \in \mathfrak{J}^{F}\right\}$.

Before switching to Model II, consider average production quantities that arise from the aggregation and that correspond to the production set-up displayed in Fig. 1. These average production quantities in question are given by expressions $\bar{D}=\|\mathfrak{I}\|^{-1} \sum \sum_{[i, t] \in \mathfrak{J}} D_{i t}, \quad \bar{L}^{l}=\|\mathfrak{J}\|^{-1} \sum \sum_{[i, t] \in \mathfrak{J}} L_{i t}^{l}$ (for all $l \in\{1, \ldots, \Omega\}$ ), $\overline{\mathbf{x}}=\|\mathfrak{J}\|^{-1} \sum \sum_{[i, t] \in \mathfrak{J}} \mathbf{x}_{i t}$ and $\overline{\mathbf{y}}=\|\mathfrak{J}\|^{-1} \sum \sum_{[i, t] \in \mathfrak{J}} \mathbf{y}_{i t}$. To this end, in the preceding enumeration and in what follows, the notation $\|S\|$ is used to indicate the cardinality of a set $S$. An appropriate normalized inflation factor for loans of type $l$ then arises in aggregated form as

$$
\frac{\left(\bar{\psi}^{l} \sum \sum_{[i, t] \in \mathfrak{I}} L_{i t}^{l}\right) /\left(\bar{\theta} \sum \sum_{[i, t] \in \mathfrak{J}} D_{i t}\right)}{\sum \sum_{[i, t] \in \mathfrak{F}} L_{i t}^{l} / \sum \sum_{[i, t] \in \mathfrak{J}} D_{i t}}=\frac{\left(\bar{\psi}^{l} \bar{L}^{l}\right) /(\bar{\theta} \bar{D})}{\bar{L}^{l} / \bar{D}}=\frac{\bar{\psi}^{l}}{\bar{\theta}},
$$

wherein $\bar{\psi}^{l}$ is the inflation factor applied to total (or average) loans of type $l$ and $\bar{\theta}$ is the deflation factor applied to total (or average) deposits. The totalling or averaging is here carried out for all loans and deposits reported in those bank-years that are contained in $\mathfrak{\Im}$.

Now the weighted normalized inflation factor that measures the unrealized potential in financial intermediation in an aggregate setting is defined in a vein similar to the case of Model I, but now with the aid of average inflation and deflation factors as $\sum_{l}\left(v_{l} \bar{\psi}^{l} / \bar{\theta}\right)$. As before, it is immediately obtained that

$$
\sum_{l=1}^{l=\Omega} v_{l} \frac{\bar{\psi}^{l}}{\bar{\theta}}=\frac{\sum_{l=1}^{l=\Omega} v_{l}\left(1+\bar{s}_{L}^{l} / \bar{L}^{l}\right)}{1-\bar{s}_{D} / \bar{D}}=\frac{1+\sum_{l=1}^{l=\Omega} v_{l}\left(\bar{s}_{L}^{l} / \bar{L}^{l}\right)}{1-\bar{s}_{D} / \bar{D}},
$$

in which $\bar{s}_{L_{-}}^{l}$ and $\bar{s}_{D}$ are non-negative quantities that satisfy $\bar{\psi}^{l}=1+\bar{s}_{L}^{l} / \bar{L}^{l}$ and $\bar{\theta}=1-\bar{s}_{D} / \bar{D}$, and that represent the shortfall in average loans of type $l$ and the excess in average deposits, respectively. So, again, the weighted normalized inflation 
factor is the reciprocal of the associated WSBM defined for average loans of different types and average deposits where the aggregation is done for all bank and time indices in $\mathfrak{\Im}$.

In step with these developments and in analogy to Model I, Model II is built upon the following fractional program helpful in identifying the missed potential in financial intermediation with the aggregation happening for all bank and time indices encompassed in $\mathfrak{J}$

$$
\min \rho_{\mathfrak{\Im}}=\frac{1-\bar{s}_{D} / \bar{D}}{1+\sum_{l=1}^{l=\Omega} v_{l}\left(\bar{s}_{L}^{l} / \bar{L}^{l}\right)}
$$

subject to

$$
\begin{aligned}
& \sum \sum_{[i, t] \in \mathfrak{J}^{F}} \lambda_{i t} D_{i t}=\bar{D}-\bar{s}_{D} \\
& \sum \sum_{[i, t] \in \mathfrak{F}^{F}} \lambda_{i t} L_{i t}^{l}=\bar{L}^{l}+\bar{s}_{L}^{l} \quad(\text { for } \quad \forall l \in\{1, \ldots, \Omega\}), \\
& \sum \sum_{[i, t] \in \mathfrak{J}^{F}} \lambda_{i t} \mathbf{x}_{i t} \leqslant \overline{\mathbf{x}}, \quad \sum \sum_{[i, t] \in \mathfrak{J}^{F}} \lambda_{i t} \mathbf{y}_{i t} \geqslant \overline{\mathbf{y}} \\
& \bar{s}_{D} \leqslant\left(1-\theta^{-}\right) \bar{D} \\
& \left.\bar{s}_{D} \geqslant 0 \quad \text { and } \quad \bar{s}_{L}^{l} \geqslant 0 \quad \text { (for } \quad \forall l \in\{1, \ldots, \Omega\}\right) \text {, } \\
& \lambda_{i t} \geqslant 0 \quad\left(\text { for } \quad \forall[i, t] \in \mathfrak{J}^{F}\right) \quad\left(\text { and optionally } \quad \sum \sum_{[i, t] \in \mathfrak{J}^{F}} \lambda_{i t}=1\right) .
\end{aligned}
$$

The construction of (7) is identical to (4), but now the optimization is carried out with the quantities averaged for $\mathfrak{\Im}$ and the optimization conditions appearing in (7a)-(7f) are required to hold for production averages computed from all banks and times comprised in $\mathfrak{\Im}$.

The relevant output of Model II in the optimal solution to (the linearized version of) program (7) for a policy-maker is again the optimal weighted average normalized inflation factor $\rho_{\mathfrak{J}}^{*-1}$ as well as the optimal values of slacks in deposits $\|\mathfrak{I}\| \cdot \bar{s}_{D}^{*}$ and loans of different categories $\|\mathfrak{I}\| \cdot \bar{s}_{L}^{l *}$ with the interpretation transcended from that of Model I. Since the optimal slacks $\|\mathfrak{I}\| \cdot \bar{s}_{D}^{*}$ and $\|\mathfrak{I}\| \cdot \bar{s}_{L}^{l *}$ are multiplied by $\|\mathfrak{I}\|$, they answer to totals calculated for all bank-years encompassed in $\mathfrak{\Im}$.

Note that the groundwork for Model II that shapes its formulation in program (7) is the definition of normalized inflation factors. It would be ideal to take a completely different route. Suppose now that that the definitional outset of the normalized inflation factor for loans of type $l$ in (5) is perhaps more appropriate. If the normalized inflation factor is put related to the missed potential over individual bank-years in $\mathfrak{I}$ instead of all bank-years in $\mathfrak{I}$ en bloc, then (5) becomes 


$$
\frac{\sum \sum_{[i, t] \in \mathfrak{S}} \psi_{i t}^{l} L_{i t}^{l} / \sum \sum_{[i, t] \in \mathfrak{S}} \theta_{i t} D_{i t}}{\sum \sum_{[i, t] \in \mathfrak{S}} L_{i t}^{l} / \sum \sum_{[i, t] \in \mathfrak{S}} D_{i t}}=\frac{\sum \sum_{[i, t] \in \mathfrak{J}} \psi_{i t}^{l}\left(L_{i t}^{l} / \sum \sum_{[i, t] \in \mathfrak{S}} L_{i t}^{l}\right)}{\sum \sum_{[i, t] \in \mathfrak{S}} \theta_{i t}\left(D_{i t} / \sum \sum_{[i, t] \in \mathfrak{J}} D_{i t}\right)}=\frac{\bar{\psi}^{l}}{\bar{\theta}},
$$

wherein $\bar{\psi}^{l}=\sum \sum_{[i, t] \in \mathfrak{J}} \psi_{i t}^{l}\left(L_{i t}^{l} / \sum \sum_{[i, t] \in \mathfrak{I}} L_{i t}^{l}\right)$ is the average inflation factor applied to loans of type $l$ and $\bar{\theta}=\sum \sum_{[i, t] \in \mathfrak{I}} \theta_{i t}\left(D_{i t} / \sum \sum_{[i, t] \in \mathfrak{I}} D_{i t}\right)$ is the average deflation factor applied to deposits. The weights are derived from shares of loans $L_{i t}^{l}$ and deposits $D_{i t}$ on their total aggregates $\sum \sum_{[i, t] \in \mathfrak{J}} L_{i t}^{l}$ and deposits $\sum \sum_{[i, t] \in \mathfrak{J}} D_{i t}$, respectively. A natural interpretation can be assigned to these weights in standard cases. When such a formulation is applied to the entire sector for one particular time, then these weights are shares of individual banks on the loans of type $l$ and deposits of the entire sector. Likewise, when it is applied to a bank in the entire period, then these weights capture how the production of loans and collection of deposits by the bank was distributed over the entire period. As a consequence-the normalized inflation factor in (6) transforms by consecutive simplifications into

$$
\begin{aligned}
\sum_{l=1}^{l=\Omega} v_{l} \frac{\bar{\psi}^{l}}{\bar{\theta}}= & \frac{\sum_{l=1}^{l=\Omega} v_{l} \bar{\psi}^{l}}{\bar{\theta}}=\frac{\sum_{l=1}^{l=\Omega} v_{l} \sum \sum_{[i, t] \in \mathfrak{T}} \psi_{i t}^{l}\left(L_{i t}^{l} / \sum \sum_{[i, t] \in \mathfrak{I}} L_{i t}^{l}\right)}{\sum \sum_{[i, t] \in \mathfrak{T}} \theta_{i t}\left(D_{i t} / \sum \sum_{[i, t] \in \mathfrak{T}} D_{i t}\right)} \\
= & \frac{\sum_{l=1}^{l=\Omega} v_{l} \sum \sum_{[i, t] \in \mathfrak{T}}\left(1+s_{L, i t}^{l} / L_{i t}^{l}\right)\left(L_{i t}^{l} / \sum \sum_{[i, t] \in \mathfrak{T}} L_{i t}^{l}\right)}{\sum \sum_{[i, t] \in \mathfrak{T}}\left(1-s_{D, i t} / D_{i t}\right)\left(D_{i t} / \sum \sum_{[i, t] \in \mathfrak{T}} D_{i t}\right)} \\
= & \frac{1+\sum_{l=1}^{l=\Omega} v_{l}\left(\sum \sum_{[i, t] \in \mathfrak{T}} s_{L, i t}^{l} / \sum \sum_{[i, t] \in \mathfrak{T}} L_{i t}^{l}\right)}{1-\sum \sum_{[i, t] \in \mathfrak{T}} s_{D, i t} / \sum \sum_{[i, t] \in \mathfrak{T}} D_{i t}},
\end{aligned}
$$

in which $\sum \sum_{[i, t] \in \mathfrak{S}} s_{L, i t}^{l}$ is the total slack amount of shortfall in loans of type $l$ and $\sum \sum_{[i, t] \in \mathfrak{I}} S_{D, i t}$ is the total slack amount of excesses in deposits.

The described developments suggest the following fractional program that is drawn up for all bank-years in $\mathfrak{J}$ and that builds directly on individual bank-year data rather than on average production quantities

$$
\min \rho_{\mathfrak{\Im}, \text { ind }}=\frac{1-\sum \sum_{[o, \tau] \in \mathfrak{J}} s_{D, i t} / \sum \sum_{[o, \tau] \in \mathfrak{T}} D_{i t}}{1+\sum_{l=1}^{l=\Omega} v_{l}\left(\sum \sum_{[o, \tau] \in \mathfrak{S}} s_{L, i t}^{l} / \sum \sum_{[o, \tau] \in \mathfrak{S}} L_{i t}^{l}\right)}
$$

subject to

$$
\sum \sum_{[i, t] \in \mathfrak{F}^{F}} \lambda_{i t} D_{i t}=D_{o \tau}-s_{D, o \tau} \quad(\text { for } \quad \forall[o, \tau] \in \mathfrak{\Im}),
$$

$\sum \sum_{[i, t] \in \mathfrak{F}^{F}} \lambda_{i t} L_{i t}^{l}=L_{o \tau}^{l}+s_{L, o \tau}^{l} \quad$ (for $\quad \forall[o, \tau] \in \mathfrak{J} \quad$ and $\quad \forall l \in\{1, \ldots, \Omega\}$ ),

$$
\sum \sum_{[i, t] \in \mathfrak{\Im}^{F}} \lambda_{i t} \mathbf{x}_{i t} \leqslant \mathbf{x}_{o \tau} \quad(\text { for } \quad \forall[o, \tau] \in \mathfrak{\Im}),
$$




$$
\begin{gathered}
\sum \sum_{[i, t] \in \mathfrak{I}^{F}} \lambda_{i t} \mathbf{y}_{i t} \geqslant \mathbf{y}_{o \tau} \quad(\text { for } \quad \forall[o, \tau] \in \mathfrak{I}), \\
s_{D, o \tau} \leqslant\left(1-\theta^{\text {lower }}\right) D_{o \tau} \quad(\text { for } \quad \forall[o, \tau] \in \mathfrak{I}), \\
s_{D, o \tau} \geqslant 0 \quad \text { and } \quad s_{L, o \tau}^{l} \geqslant 0 \quad(\text { for } \quad \forall l \in\{1, \ldots, \Omega\}), \\
\lambda_{i t} \geqslant 0 \quad\left(\text { for } \quad \forall[i, t] \in \mathfrak{J}^{F}\right) \quad\left(\text { and optionally } \quad \sum \sum_{[i, t] \in \mathfrak{F}^{F}} \lambda_{i t}=1\right) .
\end{gathered}
$$

Much of program (10) is an analogy of programs (4) and (7) presented earlier, but now the optimization is undertaken with respect to all bank-years in $\mathfrak{J}$ and also the conditions in (10a)-(10f) are stipulated for all production quantities comprised in $\mathfrak{\Im}$ on an individual basis. Of import to a policy-maker are again the optimal solution $\rho_{\mathfrak{\Im} \text {,ind }}^{*}$ and the aggregate optimal solutions for slacks in deposits $\sum \sum_{[o, \tau] \in \mathfrak{J}} s_{D, o \tau}^{*}$ and different categories of loans $\sum \sum_{[o, \tau] \in \mathfrak{I}} s_{L, o \tau}^{l *}$.

Nonetheless, the direct implementation of Model II in the variation described by program (10) may be impractical and the fractional program in (10) per se necessitates optimizing for $\|\mathfrak{I}\|$ slacks in deposits, $\Omega \cdot\|\mathfrak{I}\|$ slacks in loans and $\left\|\mathfrak{I}^{F}\right\|$ intensity variables $\lambda_{i t}$. At any rate, a more serious issue is that for many situations program (10) may be infeasible by reason of the numerous constraints that are listed in (10a)-(10c) and specified for every bank-year in $\mathfrak{\Im}$. In the authors' experience, infeasibility occurs frequently and even in cases when the aggregation in $\mathfrak{\Im}$ goes over slightly heterogeneous banks (e.g. three or four banks in a particular year) under the optional condition of variable returns to scale in (10f). In such cases, it is not possible to find a common set of intensity variables $\lambda_{i t}$ that would satisfy the conditions declared in (10a)-(10c). Note that Model II formulated in (7), unlike the version formulated in (10), is not troubled by infeasibility since it optimizes for the average quantities computed as non-weighted and simple convex combinations of original production activities. Unfortunately, it transpires that the more comprehensive formulation laid down in (10) is visited by the infeasibility issue too frequently, which is a serious hindrance to its usefulness.

The said issue may be partially rectified and alleviated by turning to different representations that provide lower and upper bounds for a feasible solution to (10). In spite of the fact that these bounds are technically workable under the proviso that a solution to (10) exists, their construction lends a more lenient interpretation and utilization. The programs of Model I in (4) and of Model II in (7) after the appropriate Charnes-Cooper transformation transpire to be handy in providing informative lower and upper bounds for the optimal solution of (10).

Interestingly, a lower bound for $\rho_{\mathfrak{T} \text {,ind }}^{*}$ (and $\rho_{\mathfrak{J} \text {,ind }}^{*-1}$ ) is provided by program (7) itself. An upper bound is obtained by applying Model I individually for all bank and time indices $[o, \tau]$ included in $\mathfrak{J}$ and collecting all individual optimal solutions for slacks in deposits $s_{D, o \tau \text {,Model I }}^{*}$ and loans of different categories $s_{L, o \tau, \text { Model I }}^{l *}$ The right-hand subscripts added to the notation signalize that the quantities in question result from the use of Model I. The optimized slacks computed hereby for individual bank-years are totalled and then substituted into the expression 


$$
\rho_{\mathfrak{\Im}, \text { Model I }}^{*}=\frac{1-\sum \sum_{[o, \tau] \in \mathfrak{T}} s_{D, o \tau, \text { Model I }}^{*} / \sum \sum_{[o, \tau] \in \mathfrak{T}} D_{i t}}{1+\sum_{l=1}^{l=\Omega} v_{l}\left(\sum \sum_{[o, \tau] \in \mathfrak{I}} s_{L, o \tau, \text { Model I }}^{l *} / \sum \sum_{[o, \tau] \in \mathfrak{T}} L_{i t}^{l}\right)} .
$$

Having all these components assembled, a series of inequalities provides the desired bounds that are valid under the proviso that an optimal solution to (10) exists: for WSBMs $\rho_{\Im}^{*} \leq \rho_{\Im}^{*}$,ind $\leq \rho_{\Im}^{*}$,Model I (and equivalently for indices of financial intermediation $\rho_{\mathfrak{J}, \text { Model I }}^{*-1} \geq \rho_{\Im}^{*-1} \geq \rho_{\mathfrak{J}}^{*-1}$ ), then for slacks in deposits $\sum \sum_{[, \tau] \in \mathfrak{I}}$ $s_{D, o \tau, \text { Model I }}^{*} \leq \sum \sum_{[o, \tau] \in \mathfrak{I}} s_{D, o \tau}^{*} \leq\|\mathfrak{I}\| \cdot \bar{s}_{D}^{*}$ as well as for slacks in different categories of loans $\sum \sum_{[o, \tau] \in \mathfrak{F}} s_{L, o \tau, \text { Model I }}^{l *} \leq \sum \sum_{[o, \tau] \in \mathfrak{S}} s_{L, o \tau, \text { Model I }}^{* *} \leq \sum \sum_{[o, \tau] \in \mathfrak{S}} s_{L, o \tau}^{l *} \leq\|\mathfrak{\Im}\| \cdot \bar{s}_{L}^{l *}$. To see this, first recognize that $\rho_{\Im \text {,ind }}$ in (10) can be restated in terms of average quantities in a fashion compliant to $\rho_{\mathfrak{\Im}}$ in (7), which follows from adopting two ancillary transcriptions in the form: $\|\mathfrak{I}\| \cdot \bar{s}_{D}=\sum \sum_{[o, \tau] \in \mathfrak{I}} s_{D, o \tau}$ for deposits and $\|\mathfrak{I}\| \cdot \bar{s}_{L}^{l}=\sum \sum_{[o, \tau] \in \mathfrak{I}} s_{L, o \tau}^{l}$ for loans of category $l$. This averaging representation appertains also to conditions (10a) to (10e) leaving condition (10f) unaffected. Despite the possibility of presenting program (10) through average quantities, what divorces both programs (10) and (7) is their conditions. It is obvious that any averaging representation of the solution to program (10) arising from the adopted transcriptions satisfies the conditions of program (7), but this does not hold vice versa. The solution of program (7) may fail to satisfy one or more constraints (10a)-(10e) expressed as averages. In other words, the average optimal solution to (7) may be not connected to individual components so that all constraints in (10) are fully satisfied. In consequence, $\rho_{\mathfrak{\Im}}^{*} \leq \rho_{\Im \text {, ind }}^{*}, \sum \sum_{[o, \tau] \in \mathfrak{I}} s_{D, o \tau}^{*} \leq\|\mathfrak{I}\| \cdot \bar{s}_{D}^{*}$ and $\sum \sum_{[o, \tau] \in \mathfrak{J}} s_{L, o \tau}^{l *} \leq\|\mathfrak{I}\| \cdot \bar{s}_{L}^{* *}$. As far as the other parts of the inequalities are concerned, $\rho_{\Im, \text { Model I }}^{*}$ does not follow from the global minimization over all bank and time indices in $\mathfrak{I}$ as pursued in (10); therefore, it is apparent that the resulting optimals may not be so severe. An immediate consequence of this observation is that $\rho_{\mathfrak{\Im} \text {,ind }}^{*} \leq \rho_{\Im \text { J,Model I }}^{*}, \quad \sum \sum_{[o, \tau] \in \mathfrak{I}} s_{D, o \tau \text {,Model I }}^{*} \leq \sum \sum_{[o, \tau] \in \mathfrak{S}} s_{D, o \tau}^{*}$ and $\sum \sum_{[o, \tau] \in \mathfrak{J}} s_{L, o \tau, \text { Model I }}^{l *} \leq \sum \sum_{[o, \tau] \in \mathfrak{J}} s_{L, o \tau}^{l *}$.

The tightness of these bounds cannot be determined a priori, but the demonstration of the proposed framework to the Slovak banking sector suggests that these bounds are practical. On the one hand, the index of financial intermediation originating from program (10) seems more suited to measuring the aggregate attainment in financial intermediation. On the other hand, the sternness of conditions renders this approach unattractive. Nonetheless, the attainment in financial intermediation for aggregate bank-years is still measurable by accepting a construal to lost potential in financial intermediation under which improvements must be sought in terms of average or en block quantities appertaining to the entire set of bank-years in $\mathfrak{\Im}$. In this regard, the index of financial intermediation supplied by Model II described in program (7) provides not only an independent legitimate metric for measuring the attainment in financial intermediation, but also a lower bound for the index coming from program (10) 


\section{Demonstration for Slovak commercial banks}

The model devised for measuring the attainment in financial intermediation is applied here and demonstrated for Slovak commercial banks for the period from 2008 to 2016. The 9-year time frame spans compactly years of favourable development for the Slovak economy and stability for the Slovak banking sector. The model of financial intermediation postulated and adopted for Slovak commercial banks derives from their business models that traditionally rely on traditional depository and creditory services. Investments do not dominate their balance sheets and financial products (such as mutual fund shares) that are sold also by Slovak commercial banks do not appear in the balance sheets and are a minor part of banking activities. Interpreting financial intermediation through depository and creditory operations is thus perfectly apposite in this context and the specification reducing financial intermediation to taking deposits and providing loans of different categories is reasonable.

The data came from separate IFRS financial statements of individual Slovak banking institutions (both commercial banks per se and branch offices of foreign banks) compiled by TREND Analyses of News and Media Holding, a. s. (the former TREND Holding, s. r. o.). The data sample covered the period of 9 years from 2008 to 2016; yet, the nominal number of commercial banks across these years varied between 7 (in 2015 and 2016) and 13 (in 2008 and 2011). In total, the sample contained nominally 91 bank-year observations. ${ }^{2}$ The effective number of observations was affected by missingness of some data points usually due to exits or late entries of some banks in the sample. The year-end balance sheet items stated in thousand $€$ were properly deflated by the implicit price deflator published by Eurostat to assure their comparability. The data set was investigated for a presence of outlying values by dint of the identification method developed by Wilson (1993) without finding out anomalous data points. It is true that the largest banks (SLSP, TATRA and VUB) are somewhat separated from the rest of the data, which may present grounds for preferring the VRS technology.

The model of banking production assumed here for Slovak commercial banks is standard and complies with the familiar intermediation approach as it is called in efficiency studies. The model recognizes three inputs and two outputs. The inputs are labour force measured by the number of employees (NoE), physical capital measured by total fixed assets (TFA) and total deposits (TD), whereas the outputs

\footnotetext{
${ }^{2}$ The data set had the following representation (whereas parentheses state the number of years for which data were available and brackets with bold fond indicate tags adopted for further presentation): Crédit Agricole Corporate and Investment Bank SA, foreign branch (4) [CAC], Československá obchodná banka, a.s. (6) [CSOB], ING Bank N.V., foreign branch (4) [ING], Istrobanka, a.s. (1) [ISTRO], Komerční banka Bratislava, a.s./Komerční banka, a.s., foreign branch (7) [KOBA], Oberbank AG, foreign branch (8) [OBER], OTP Banka Slovensko, a.s. (9) [OTP], Poštová banka, a.s. (6) [POBA], Dexia banka Slovensko a.s./Prima banka Slovensko, a.s. (9) [PRIMA], Sberbank Slovensko, a.s. (8) [SBER], Slovenská sporitel'ňa, a.s. (9) [SLSP], Tatra banka, a.s. (9) [TATRA], UniBanka, a.s./UniCredit Bank Slovakia a.s./UniCredit Bank Czech Republic and Slovakia, a.s., foreign branch (9) [UNICB], Všeobecná úverová banka, a.s. (8) [VUB].
} 
Table 1 Statistical summary of the data sample

\begin{tabular}{lrrrrrr}
\hline Descriptor & NoE & \multicolumn{1}{c}{ TFA } & \multicolumn{1}{c}{ TDA } & TL & TL_corp & TL_other \\
\hline Number of values & 91 & 91 & 91 & 91 & 91 & 91 \\
Minimum & 16 & 127 & 10,510 & 11,617 & 11,289 & 328 \\
Maximum & 4805 & 249,308 & $10,565,303$ & $9,748,711$ & $3,478,459$ & $7,849,200$ \\
Mean & 1532 & 59,499 & $3,000,888$ & $2,691,784$ & $1,121,505$ & $1,570,279$ \\
SD & 1486 & 66,400 & $2,945,338$ & $2,607,042$ & 928,843 & $1,847,523$ \\
\hline
\end{tabular}

$\mathrm{NoE}$ is expressed in yearly average full-time equivalents, whilst the other balance sheet variables are expressed in $€$ of 2005 prices

are loans to the corporate sector (TL_corp) and other loans (TL_other). Both loan variables considered, TL_corp and TL_other, amount to total loans provided (TL). NoE is expressed in yearly average full-time equivalents, whereas all the other variables reported on the balance sheet are all expressed as end-year amounts (being adjusted by the implicit price deflator to 2005 prices). The insertion of employees and fixed assets into considerations on the side of inputs follows from a classical economic view upon the transformation process, during which factors of production (such as natural resources, the capital stock and labour) are transmuted into outputs. Beyond any doubt, labour force is one of the key factors of productivity growth in the banking sector, and its inclusion through employee numbers takes on relevance as confronting a decreasing trend of the number of employees with an increase of total assets in the Slovak banking industry. The specification of deposits as an input and corporate and other loans as outputs then accords with the premise underlying financial intermediation, i.e. that banks transform deposits into loans. The model of banking production is not discordant from the convention in this area as follows, for example, from Heffernan (2005, pp. 474-476) or Ahn and Le (2014, pp. 7-9), and implies that $P=2$ and $R=0$ if sticking to the notation introduced at the outset of the previous section. ${ }^{3}$

The basic descriptive statistics for the data sample are reported in Table 1 and exhibit a large amount of heterogeneity between commercial banks in the sample, which is a feature displayed by most production data. The sample consists of large and small "normal" commercial banks as well as branch offices of foreign banks. An implicit assumption embedded in any production model is the isotonicity of inputs and outputs, i.e. that outputs do not decrease with increasing inputs (e.g. Thanassoulis et al. 2008, p. 301). Albeit the economic rationale of the present model

\footnotetext{
3 Some applied DEA studies in banking incline to specify cost measures of utilized or consumed resources (inputs) in place of physical representations of utilization or consumption (see, for example, Fortin and Leclerc 2007, Table 1). In this vein, labour is, for example, measured or proxied by labour expense and total fixed assets by operational (non-interest) expense. Although rather common, this practice intermixes technical aspects of banking production with allocative aspects, and the resulting efficiency score is related neither to technical efficiency nor economic efficiency (especially in the case when voluminous measures such as deposits and loans are employed beside cost measures such as noninterest expense and revenue. The specification of voluminous measures of production variables entertained here is referred to by Ahn and Le (2014, p. 21) as the asset-oriented approach.
} 
is not suggestive of any violation of the isotonicity property, the suitability of the input-output specification may also be substantiated more thoroughly. There is a lately established convention of formal checking the relationship between inputs and outputs that bases upon inspection of the correlation matrix (e.g. Chiu et al. 2014; Hong and Jeong2019; Mitropoulos and Mitropoulos 2020). The correlation coefficients between the variables, three inputs (NoE, TFA and TD) and two outputs (TL_corp and TL_other), are all positive and greater than 0.75 . In addition, a canonical correlation analysis attests to a high level of significant association of inputs and outputs since the first canonical correlation is 0.9598 with Roy's largest root 0.9212 and a virtually zero $p$ value produced by a standard F-approximation (see, for example, Muirhead 1982, pp. 548-571; Venables 1974). The composition of the first canonical variates indicates that there are some substitution effects between NoE and TFA (to some extent labour force can be substituted for fixed assets, and vice versa), but the canonical loadings (correlation coefficients between production variables and canonical covariates) confirm that the inputs contribute to the outputs. The correlation coefficients between NoE, TFA and TD and the output first canonical variate are $0.9198,0.8481$ and 0.9554 , whereas between TL_corp and TL_other and the input canonical variate are 0.9250 and 0.9473 . Since canonical correlation analysis hinges gravely upon multivariate normality, the reported figures come from logarithmized values of the production variables, although with almost no quantitative

Table 2 Identified indices of financial intermediation for banks in the data sample

\begin{tabular}{|c|c|c|c|c|c|c|c|c|c|c|c|c|}
\hline Bank & 2008 & 2009 & 2010 & 2011 & 2012 & 2013 & 2014 & 2015 & 2016 & $\mathrm{FI}_{\mathrm{MII}(7)}$ & $\mathrm{FI}_{\mathrm{up}(11)}$ & $\mathrm{FI}_{\text {ind }(10)}$ \\
\hline$A C$ & 2.307 & 1.000 & 1.000 & 1.000 & NA & NA & NA & NA & NA & 1.171 & 1.357 & NA \\
\hline CSOB & 2.639 & 1.556 & 1.635 & 1.451 & 1.738 & 1.925 & NA & NA & NA & 1.723 & 1.754 & NA \\
\hline ING & 2.630 & 1.000 & 1.931 & 1.197 & NA & NA & NA & NA & NA & 1.569 & 1.677 & NA \\
\hline ISTRO & 2.373 & NA & NA & NA & NA & NA & NA & NA & NA & 2.373 & 2.373 & 2.373 \\
\hline KOBA & 4.638 & NA & NA & 1.000 & 1.000 & 1.000 & 1.070 & 1.000 & 1.000 & 1.124 & 1.267 & NA \\
\hline OBER & NA & 1.000 & NA & 2.682 & 2.970 & 2.997 & 1.709 & 1.432 & 1.000 & 1.880 & 2.065 & NA \\
\hline OTP & 2.178 & 2.012 & 2.156 & 2.456 & 2.625 & 2.444 & 2.629 & 2.455 & 2.123 & 2.310 & 2.350 & NA \\
\hline POBA & 4.150 & 3.442 & 3.047 & 2.133 & 1.971 & 1.518 & NA & NA & NA & 2.372 & 2.863 & NA \\
\hline PRIMA & 2.307 & 1.975 & 1.151 & 2.879 & NA & NA & NA & NA & NA & 1.955 & 2.136 & NA \\
\hline SBER & 2.339 & 1.688 & 1.682 & 1.705 & 1.755 & 1.890 & 1.395 & 2.175 & NA & 1.763 & 1.844 & NA \\
\hline SLSP & 2.533 & 1.506 & 1.717 & 1.557 & 1.562 & 1.579 & 1.522 & 1.240 & 1.000 & 1.525 & 1.587 & NA \\
\hline TATRA & 1.519 & 1.223 & 1.168 & 1.086 & 1.124 & 1.120 & 1.000 & 1.000 & 1.000 & 1.111 & 1.139 & NA \\
\hline UNICB & 1.934 & 1.377 & 1.510 & 1.243 & 1.406 & 1.257 & 1.311 & 1.212 & 1.000 & 1.285 & 1.290 & NA \\
\hline VUB & 2.352 & 1.427 & 1.369 & 1.242 & 1.227 & 1.260 & 1.117 & NA & 1.000 & 1.299 & 1.304 & NA \\
\hline $\mathrm{FI}_{\mathrm{lo}}$ & 2.192 & 1.498 & 1.485 & 1.381 & 1.420 & 1.415 & 1.245 & 1.240 & 1.042 & & & \\
\hline $\mathrm{FI}_{\text {up }}$ & 2.674 & 1.895 & 1.873 & 1.858 & 1.820 & 1.815 & 1.620 & 1.691 & 1.287 & & & \\
\hline $\mathrm{FI}_{\mathrm{F}}$ & NA & NA & NA & NA & NA & NA & NA & NA & NA & & & \\
\hline
\end{tabular}

The codes of bank names are explained in Footnote 2. The abbreviation "FI" denotes the three aggregate versions of the financial intermediation index: "FI $\mathrm{MII}_{(7)}$ " announces the lower bound yielded by program

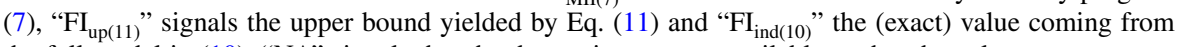
the full model in (10). "NA" signals that the data point was not available or that the value was not computable 
Table 3 Programs for calculation of the index of financial intermediation and WSBM technical efficiency score under the intermediation approach

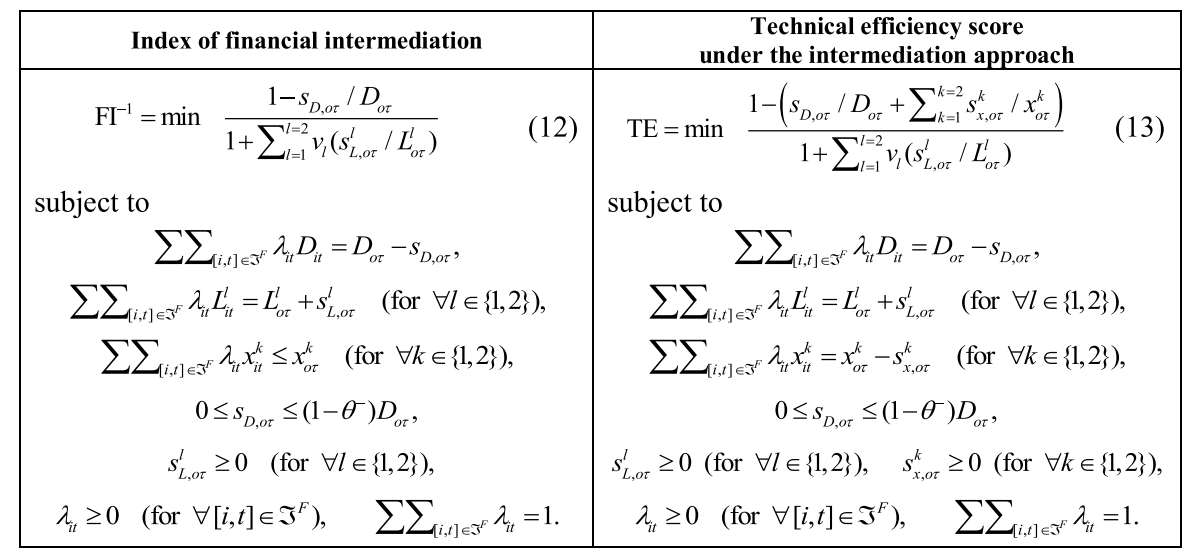

difference from those when the logarithmic transformation to improve normality is not conducted.

The relative importance of corporate loans for economic stability and growth was gauged to be threefold as high as of other loans, which entailed weights $v_{1}=0.75$ and $v_{2}=0.25$ for corporate and other loans, respectively. Setting a restriction for deposits to be deflated to a maximum of $90 \%$ of their observed amounts (specifying thus $\theta^{-}=0.90$ ) and opting for VRS produced main results reported in Table 2 and minor results shown in the three tables of "Appendix". The inside of Table 2 shows indices of financial intermediation for each of the 91 bank-years as indicated by Model I, whereas the marginal three columns and rows answer to indices of financial intermediation arising in connection with Model II. In the eventuality of excellent attainment relative to the observed best practices, deflation and inflation factors are optimized in unison at a value of one and the index of financial intermediation is found one. Hence, values of the index greater than one in Table 2 merely entail that some potential in financial intermediation was squandered. Whilst the columns present indices of financial intermediation aggregated for banks over the entire period, the rows are aggregated for years considering all the banks. The columns and rows labelled " $\mathrm{FI}_{\mathrm{MII}(7)}$ " then show indices associated with Model II computed by program (7) in which improvements in financial intermediation are perceived in respect of average quantities. The outermost arrays labelled "FI $\mathrm{ind}_{(10)}$ " display indices originating from the alternative formulation of Model II described in program (10), and up to one trivial exception for ISTRO they all are troubled by infeasibility. Finally, the columns and rows labelled "FI $\mathrm{up}_{\mathrm{up}(11)}$ " display indices that come from expression (11). The values presented under the labels " $\mathrm{FI}_{\mathrm{MII}(7)}$ " and " $\mathrm{FI}_{\mathrm{up}(11)}$ " provide lower and upper bounds for the optimal solutions of program (10) whose results are stated

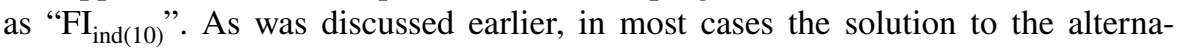
tive to Model II as formulated in (10) does not exist so these bounds are purely demonstrational. Nonetheless, the widths of the intervals implied by these bounds are quite narrow. The tables in "Appendix" then show the corresponding deflation 
factors (Table 5), and inflation factors for corporate and other loans (Tables 6, 7). The deflation factors in Table 3 testify that the specified threshold $\theta^{-}=0.90$ was hit and reached a good many times.

It must be said that the estimated indices of financial intermediation agree with the general characteristic and temporal development of the Slovak banking sector. For instance, the extraordinarily poor performance of KOBA in financial intermediation in 2008 and its rapid improvement past 2010 is just a mere consequence of a change in the business model that it managed to execute. During the few years between 2008 and 2011, the bank boosted the size of depository and creditory operations substantially whilst growing in employee numbers and fixed assets only slightly, and it also strengthened the share of corporate loans on total creditory operations. TATRA is engaged especially in financing business activities and over the past few years has waged a persistent campaign to preserve its unique status. The entrepreneurial segment is also targeted by CSOB and UNICB. The former bank in 2009 merged with ISTRO and the merger eventually led to restructuring the deposit and loan portfolios of both banks, which is discernible in more favourable indices of financial intermediation of CSOB after the merger. In addition, the intentions declared by the National Bank of Slovakia to make conditions for granting loans by commercial banks more stringent have also been communicated and emphasized over the recent period and resulted in a boost of credit activity in 2016. An uprise of interest in loans taken under mild conditions meant that various commercial banks reported higher volumes of loans and attained the most favourable performance relative to best practices.

The severity of the infeasibility issue associated with program (10) comes out well when the program is solved for even a few bank-years to be aggregated. The point is illustrated for the case when aggregation is performed for banks over the entire period and only the first two and 3 years are taken into account (providing that at least two or three such bank-years are available, which excludes ISTRO). When the first two observed years are attempted, program (10) is feasible for 6 banks (OTP with FI = 2.063, SBER with FI $=1.943$, SLSP with FI = 1.864, TATRA with $\mathrm{FI}=1.346$, UNICB with $\mathrm{FI}=1.584$ and VUB with $\mathrm{FI}=1.740$ ). Adding one more effective year lowers feasibility to 5 banks (OTP with FI=2.085, SBER with $\mathrm{FI}=1.840$, SLSP with $\mathrm{FI}=1.762$, TATRA with $\mathrm{FI}=1.276$ and VUB with $\mathrm{FI}=1.555)$.

As already underlined in the introduction, the present notion of attainment in financial intermediation should not be confused with the notion of efficiency in banking undertaking when the bank is construed as a financial intermediary. Both notions are associated with banking performance, but the former isolates sole success in asset transformation of deposits into credits, whereas the latter studies accomplishment in management of resources towards their transformation into banking outputs. Strictly speaking, only the latter notion-referred to as the intermediation approach-is associated with efficiency as an economic category. In addition, the index of financial intermediation is a function of deposits and loans as contrasts from the technical efficiency score that embodies the information about all proportions in which deposits plus other inputs are transmuted into loans and other outputs. This is apparent also from the juxtaposition 
Table 4 Confrontation of indices of financial intermediation and traditional efficiency scores corresponding to the intermediation approach

\begin{tabular}{llllc}
\hline Descriptor & $\mathrm{FI}$ & $\mathrm{FI}^{-1}$ & $\mathrm{TE}$ & $\mathrm{FI}^{-1}-\mathrm{TE}$ \\
\hline Number of values & 91 & 91 & 91 & 91 \\
Minimum & 1.000 & 0.216 & 0.125 & -0.049 \\
Maximum & 4.638 & 1.000 & 1.000 & 0.241 \\
Mean & 1.734 & 0.665 & 0.571 & 0.094 \\
Standard deviation & 0.731 & 0.231 & 0.270 & 0.077 \\
\hline
\end{tabular}

The abbreviations "FI" and " $\mathrm{FI}^{-1}$ " denote the intermediation index and its reciprocal calculated for individual bank-years by dint of program (12), whereas "TE" is the traditional WSBM score calculated under the intermediation approach adopting the weighting scheme for corporate and other weights and respecting the maximum permissible deflation of deposits

of two models provided in Table 3. Program (12) on the left-hand side of Table 3 is the model for measuring attainment in financial intermediation, and program (13) on the right-hand side is an analogous model for measuring efficiency under the intermediation approach. The choice of a WSBM model in program (13) is dictated by the fact that the index of financial intermediation has a formulation closely linked with the WSBM as was demonstrated in Sect. 2. Both programs are stated under VRS and are specialized to the particular case entertained in the demonstration, in which banking activities are understood as a production of corporate and other loans $\left(L_{i t}^{1}\right.$ and $\left.L_{i t}^{2}\right)$ as the only outputs by using labour force $\left(x_{i t}^{1}\right)$ and physical capital $\left(x_{i t}^{2}\right)$ and deposits $\left(D_{i t}\right)$ as the only inputs. So, there are no other outputs and no $y_{i t}^{\prime}$ variables to appear in the programs. Program (13) also necessitates introduction of slacks on other inputs $s_{x, i t}^{1}$ and $s_{x, i t}^{2}$ (associated with $x_{i t}^{1}$ and $x_{i t}^{2}$, respectively). To ensure comparability, the restriction for maximum permissible deflation of deposits governed by $\theta^{-}$is also implemented with program (13). The optimal solution " $\mathrm{FI}^{-1}$ " of program (12) is the inverse of the index of the financial intermediation and the optimal solution "TE" of program (13) is the WSBM technical efficiency score. The tags "FI", "FI-1" and "TE" are employed in the ensuing tabular and graphical presentation.

Albeit both programs are footed upon the same estimate of the production possibility set and the difference factually appears in the numerator of the objective function, the optimal values are not in a general mathematical link as may be observed in Table 4 and Fig. 2. For the 91 bank-years under consideration, Table 4 shows basic descriptives of the indices of financial intermediation (FI) and their reciprocals $\left(\mathrm{FI}^{-1}\right)$ produced by program (12), the technical efficiency scores (TE) estimated by using program (13) and the differences between $\mathrm{FI}^{-1}$ and TE. It is worthwhile noting that the descriptives compiled for FI in fact summarize inner values of Table 2 and that a meaningful comparison requires matching and contrasting $\mathrm{FI}^{-1}$ and TE, which is translated into differences $\mathrm{FI}^{-1}-\mathrm{TE}$. Figure 2 is perhaps more instructive and visualizes the relationship and differences that arise in measuring attainment in financial intermediation and measuring efficiency in a traditional manner. Figure 2 presents in turn three graphs: the scatter graph of $\mathrm{FI}^{-1}$ and $\mathrm{TE}$ with an identity line and a nonparametric estimate of the regression relationship, the graph juxtaposing 
estimated densities of $\mathrm{FI}^{-1}$ and $\mathrm{TE}$ and the graph of graph of the estimated density of $\mathrm{FI}^{-1}-\mathrm{TE}$ equipped with a rug plot. The scatter graph also provides values of Pearson and Spearman correlations between $\mathrm{FI}^{-1}$ and TE. Whereas the estimate of the functional relationship between $\mathrm{FI}^{-1}$ and TE was obtained by the LOWESS smoother proposed by Cleveland (1981), the estimates of probability densities of TE and $\mathrm{FI}^{-1}$ were rendered by the logspline method of Stone et al. (1997). The choice of density smoothing was guided by the fact that $\mathrm{FI}^{-1}$ and $\mathrm{TE}$ are restricted to the interval $[0,1]$ and are hence truncated, which is also the case of their difference $\mathrm{FI}^{-1}-\mathrm{TE}$.

The comparison suggests that these two performance concepts derived from the notion of financial intermediation are likely to produce different measurements, although the calculated measures of performance of $\mathrm{FI}^{-1}$ and $\mathrm{TE}$ are in the empirical demonstration roughly similar and lead to almost identical rankings (with a Spearman correlation coefficient of 0.959). Nevertheless, $\mathrm{FI}^{-1}$ and TE are not identical as mostly $\mathrm{FI}^{-1}>\mathrm{TE}$. Therefore, the index of financial intermediation shows the banks in the sample in a more favourable light than the WSBM, and average benefit of the former over the latter is 0.094 (which is the mean of the difference $\mathrm{FI}^{-1}-\mathrm{TE}$ ). In addition, the values $\mathrm{FI}^{-1}$ and $\mathrm{TE}$ have completely different distributions with a bimodal pattern for their difference $\mathrm{FI}^{-1}-\mathrm{TE}$. The prevalence of $\mathrm{FI}^{-1}$ being greater than TE and the shapes of all the three estimated densities indicate that the proposed model for measuring attainment in financial intermediation tends to yield generally a less stringent assessment than the model for measuring technical efficiency under the intermediation approach.

Owing to the complicated structure of programs (12) and (13) in Table 3, it is difficult, if not impossible, to determine under which circumstances there is a discrepancy between the assessment that is obtained by measuring attainment in financial intermediation and the assessment arising from measuring efficiency under the intermediation approach. An exploration of patterns with which input and output production variables affect the difference $\mathrm{FI}^{-1}-\mathrm{TE}$ is undertaken in Fig. 3. This exploration attempts to explain the sign and magnitude of $\mathrm{FI}^{-1}-\mathrm{TE}$ with respect to the structural links that underlying production variables and that are expressed as ratios. A plot is displayed in Fig. 3 for each of these four ratio factors: corporate to other loans (TL_corp/TL_other), total loans to deposits (TL/TD), total loans per employee (TL/NoE), total loans to total fixed assets (TL/TFA). The horizontal axes display factors and the vertical axes identify differences $\mathrm{FI}^{-1}-\mathrm{TE}$ shown as downward- or upward-oriented spikes (for negative and positive differences, respectively) or points (for no differences).

Figure 3 does not provide an explanation in which situations indices of financial intermediation are typically greater than or equal to efficiency scores answering to the intermediation approach (i.e. when $\mathrm{FI}^{-1}-\mathrm{TE} \geq 0$ is typically the case). The obvious reason is a scarcity of such occurrences. In addition, the patterns in Fig. 3 point to the seeming irrelevance of loan structure (the proportion of corporate to other loans) in explaining the magnitude of differences $\mathrm{FI}^{-1}-\mathrm{TE}$. Nonetheless, the other 

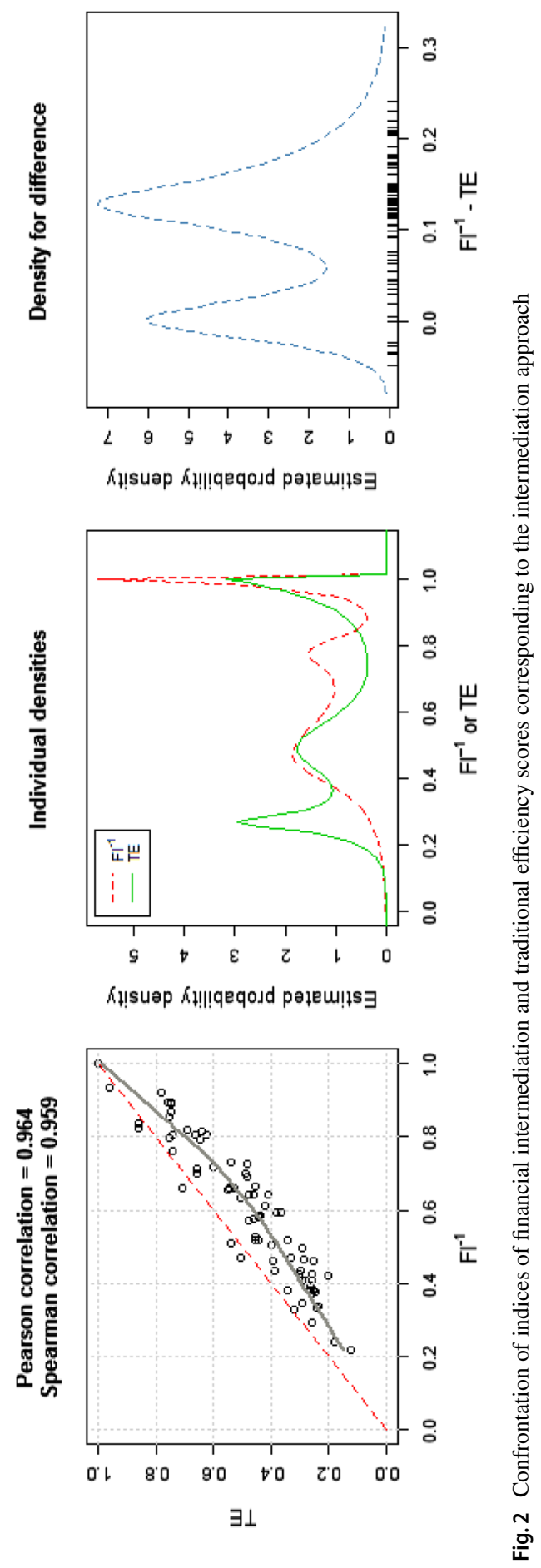
three structural factors seem effective. The largest downside differences $\mathrm{FI}^{-1}-\mathrm{TE}$ are discernible in situations when the TL/TD ratio is around 1.00 (roughly from 0.75 to 1.10 ), when the TL/NoE ratio is small (roughly up to $2000 €$ per employee) as well as when also the TL/TFA ratio is small (roughly up to 50). It is worthwhile pointing out that all these three last factors are productivity indicators, and so more stringent indices of financial intermediation are prevalent in situations when productivity of loan provision was small in comparison to (especially) labour, physical capital and (partly) deposits. In this demonstration, standard measurement of technical efficiency grounded in the intermediation approach tended to show performance of banks in the sample in a more favourable light than the proposed modelling framework. It thus appears that the proposed approach to measuring financial intermediation penalizes more significantly for low productivity in loan provision (the ultimate output of financial intermediation) as these are the cases when potential in financial intermediation is utterly realized in a low extent.

\section{Concluding remarks}

It is true that financial intermediation is thoroughly studied and assessed in the form of simple ratio indicators. Some indicators measure size of banking operations (such as banking assets to gross domestic product or banking deposits to gross domestic product) and only the loan-to-deposit ratio catches the inner legacy of financial intermediation as it juxtapose depository and creditory activities of banks or banking sectors. The proposed approach to modelling and measuring financial intermediation emphasizes the necessity to compare in a descriptive way both sides of the intermediation process and builds on the ideas of DEA to instil a normative aspect into the assessment. To the best knowledge of the authors, neither are there approaches that compare depository and creditory activities of banks or sectors aside from ratio analysis, nor are there approaches that relate depository and creditory activities to best practices. The models that are presently proposed differ only whether they are to be employed for one bank in 1 year or in aggregate form. Although their formulation is presented in conjunction with a data set consisting of bank-year observations, they are workable also in situations of cross section data observed for one particular year. Similarly, although it is spoken of deposits and several categories of loans, the models only require that banks use in financial intermediation only one input (most likely deposits) and intermediate several outputs (not only loans). The terms deposits and loans can be thought of as universal wild cards and should not be treated literally. Notwithstanding a tempting resemblance with the intermediation approach, attainment of financial intermediation must be emphatically distinguished form technical efficiency under the intermediation approach. The reason being, the former focuses merely upon success with which deposits are intermediated into loans, whereas the latter broadens its scope to include success also in non-intermediation activities and technically stipulates chiefly that deposits be 

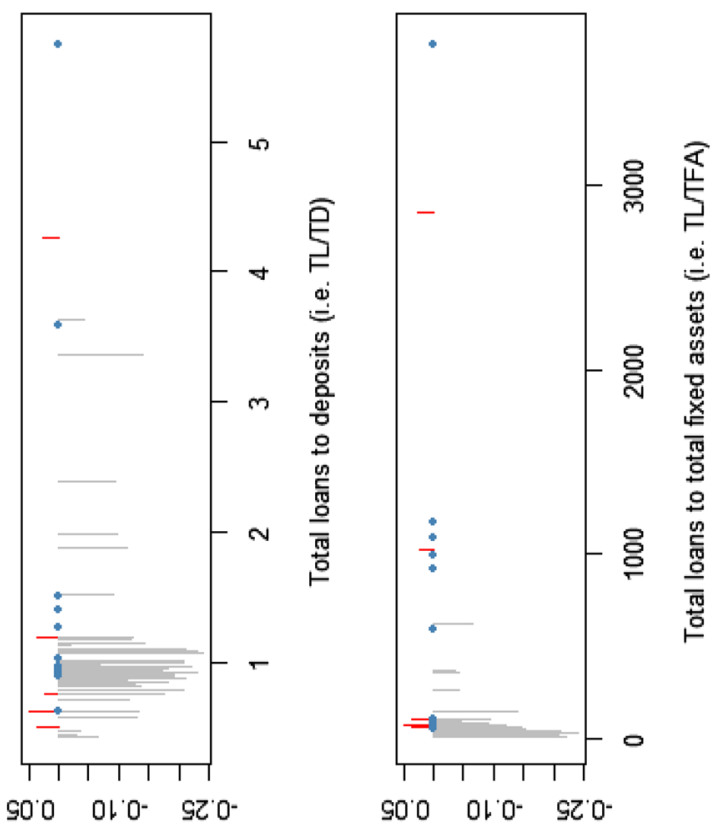

$\left.\exists \perp \cdot{ }^{\prime}-1\right]$
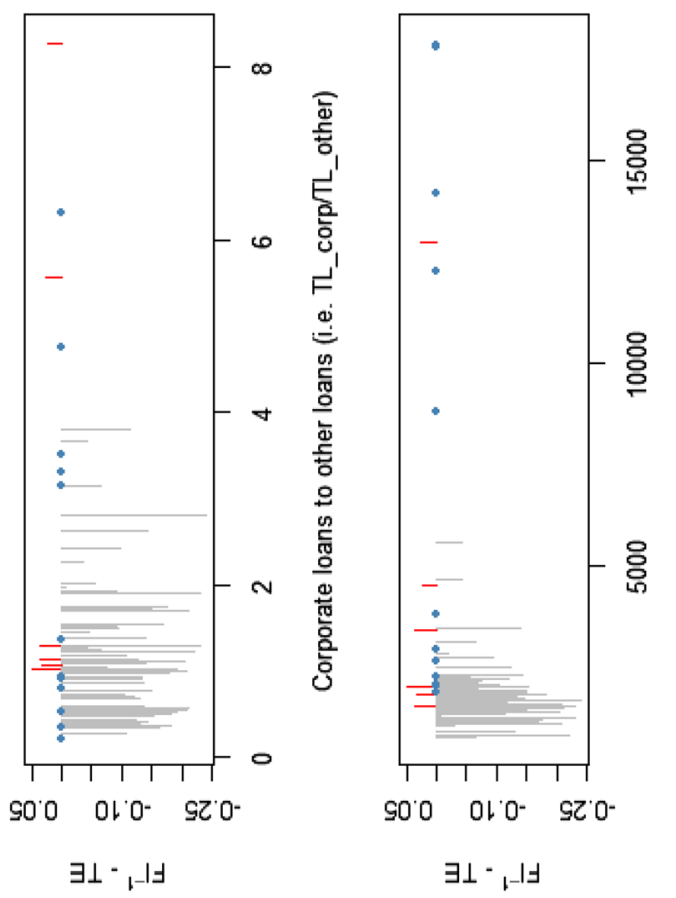

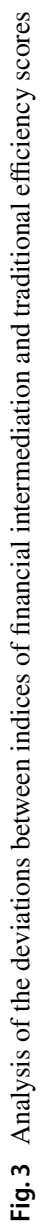


placed on the input side and loans on the output side of production. The case study demonstrated that differences between assessment may arise and do arise quite frequently, particularly in cases when loans are produced with a lower productivity of labour and physical capital.

To explain the above made allusion to wildcards, the proposed modelling framework is adaptable by replacing deposits and loans by other measures of financing activity. In this present period of economic difficulties brought about by the coronavirus pandemic, the model may be put to use in measuring financial intermediation that takes place between the European Central Bank (ECB) and national banking systems of the euro area (de Guindos and Schnabel 2020; Lagarde 2020; European Central Bank 2020). The adapted index of financial intermediation would then be a metric of the success with which the ECB disperses and channels its liquidity towards national needs with a view of encouraging banks to extend loans to economic agents with less access to credit. This interpretation of financial intermediation would substitute deposits for the presently released funds of the ECB (with a maturity up to 3 years and at negative interest rates) as well as the purchases of public and private sector bonds. Whereas the former lending facility is oriented upon micro-firms and sole proprietors, the latter purchase program seeks to ensure that all sectors of the economy can benefit from easy financing conditions. Loans would remain as they are, but would be represented by loans provided by national banking sectors. A value of the index of financial intermediation around 1 would indicate that the ECB's response to the crisis came to fruition and that banking systems in the euro area allocated all the newly available funds to national economies. A value greater than 1 would then imply that also some national resources were mobilized.

The present framework, as formulated, aims at the needs of macroeconomic policy decision-making and planning and is not yet tuned-up to the needs of regulatory assessment. The framework strives to maximize the loan-to-deposit ratio, but this maximization in regulation must respect some limits. Too small a value of the loan-to-deposit ratio is not adequate as it is generally a testimony of excessive liquidity, whereas if the value is too high, it is a sign of heightened riskiness. European banks are screened by regulatory bodies for the value of this indicator (more precisely, for loan-to-deposit ratios for households and non-financial corporations) and the risk heatmap sets that a value between 1 and 1.5 is considered as a moderate risk and a value greater than 1.5 is deemed to be an indication of considerable risk (European Banking Authority 2017). The regulatory risk threshold can be implemented into the present framework by introducing an upper bound for the resulting loan-to-deposit ratios such as the one for the deflation factors in conditions $(d)$ of all the programs. Suppose in this regard that a certain viable threshold $\eta$ was set. In theory, $\eta$ would be required positive; yet, in regulatory practice, $\eta$ could only be between 1 and (say) 2 . The regulatory condition for program (4) might read $\sum_{l}\left(L_{o \tau}^{l}+s_{L, o \tau}^{l}\right) \leq \eta\left(D_{o \tau}-s_{D, o \tau}\right)$ and for program (7) would become $\sum_{l}\left(\bar{L}^{l}+\bar{s}_{L}^{l}\right) \leq \eta\left(\bar{D}^{-}-\bar{s}_{D}\right)$. An adequate condition for program (10) would be analogical and more complicated. From a regulatory standpoint, 
the loan-to-deposit ratio that arises from these conditions puts no weights upon loans of different categories (for if some weights are assigned, they derive from the risk embodied in individual categories of loans). It should also be noted that the full implementation of such an idea would also require caution since the regulatory threshold appertains to households and non-financial corporations (here corporate loans plus other loans). Several thresholds can be considered and the assessment may proceed in the spirit of a regulatory sensitivity analysis. Nonetheless, the suggested alteration of the presently proposed framework to make it more compliant with regulatory needs would predestine a different interpretation and use.

Another route worthy of exploration to tackling the definition of the index of financial intermediation is, for example, is constructing the weighted normalized inflation factor in the spirit of a geometric mean. The index of financial intermediation would become $\Pi_{l}\left(\psi_{i t}^{l} / \theta_{i t}\right)^{v_{l}}$, which would eventually lead to a version of the geometric distance function devised by Portela and Thanassoulis (2005, 2007). The price to pay would be nonlinearities injected in the model that ensues.

One more issue is that any choice of weights required to differentiate between diverse categories of loans is subjective and prone to criticism. This may be mended by conducting an ex post stochastic sensitivity analysis that accommodates different specifications of such weights that still comply with the analyst's a priori views. A viable approach is to adapt and extend the procedure suggested by Bod'a (2017) in a context of modelling market shares.

Finally, indices of financial intermediation yielded by the model may be useful not only in explorations of the finance-growth nexus as neat proxies of financial development (e.g. Ho and Iyke 2018; Olaniyi and Oladeji 2020), but also as contextual variables in a two-stage DEA analysis of banking efficiency (e.g. Banya and Biekpe 2018) or in assessments of financial stability and transparency (e.g. Bashir et al. 2020; Dutta and Mukherjee 2018).

Acknowledgements This paper arose in partial fulfilment of project VEGA \# 1/0608/19.

\section{Compliance with ethical standards}

Conflict of interest The authors declare that they have no conflict of interest.

\section{Appendix}

See Tables 5, 6 and 7. 
Table 5 Identified deposit deflation factors for banks in the data sample

\begin{tabular}{lllllllllllll}
\hline Bank & 2008 & 2009 & 2010 & 2011 & 2012 & 2013 & 2014 & 2015 & 2016 & $\theta_{\text {MII }(7)}$ & $\theta_{\text {up }}$ & $\theta_{\text {ind(10) }}$ \\
\hline CAC & 0.964 & 1.000 & 1.000 & 1.000 & NA & NA & NA & NA & NA & 0.900 & 0.994 & NA \\
CSOB & 0.900 & 0.900 & 0.900 & 0.900 & 0.900 & 0.900 & NA & NA & NA & 0.900 & 0.900 & NA \\
ING & 0.900 & 1.000 & 0.900 & 0.900 & NA & NA & NA & NA & NA & 0.900 & 0.924 & NA \\
ISTRO & 0.900 & NA & NA & NA & NA & NA & NA & NA & NA & 0.900 & 0.900 & 0.900 \\
KOBA & 0.900 & NA & NA & 1.000 & 1.000 & 1.000 & 0.940 & 1.000 & 1.000 & 0.900 & 0.982 & NA \\
OBER & NA & 1.000 & NA & 1.000 & 1.000 & 1.000 & 1.000 & 1.000 & 1.000 & 1.000 & 1.000 & NA \\
OTP & 0.900 & 0.900 & 0.900 & 0.912 & 0.926 & 1.000 & 0.992 & 1.000 & 1.000 & 0.951 & 0.952 & NA \\
POBA & 0.900 & 0.900 & 0.900 & 0.900 & 0.900 & 0.900 & NA & NA & NA & 0.900 & 0.900 & NA \\
PRIMA & 0.900 & 0.950 & 1.000 & 1.000 & NA & NA & NA & NA & NA & 0.992 & 0.962 & NA \\
SBER & 0.900 & 0.900 & 0.900 & 0.900 & 0.900 & 0.900 & 1.000 & 1.000 & NA & 0.900 & 0.928 & NA \\
SLSP & 0.900 & 0.900 & 0.900 & 1.000 & 1.000 & 1.000 & 0.963 & 0.929 & 1.000 & 1.000 & 0.957 & NA \\
TATRA & 0.900 & 0.900 & 0.900 & 0.945 & 0.900 & 0.900 & 1.000 & 1.000 & 1.000 & 0.900 & 0.943 & NA \\
UNICB & 0.900 & 0.900 & 0.900 & 0.974 & 0.900 & 0.900 & 0.900 & 0.900 & 1.000 & 0.900 & 0.920 & NA \\
VUB & 0.900 & 0.900 & 0.900 & 0.900 & 0.900 & 0.900 & 1.000 & NA & 1.000 & 0.900 & 0.929 & NA \\
$\theta_{\text {lo }}$ & 0.900 & 0.900 & 0.900 & 0.900 & 0.900 & 0.900 & 0.958 & 0.943 & 1.000 & & & \\
$\theta_{\text {up }}$ & 0.900 & 0.906 & 0.906 & 0.942 & 0.925 & 0.928 & 0.978 & 0.958 & 1.000 & & & \\
$\theta_{\text {F }}$ & NA & NA & NA & NA & NA & NA & NA & NA & NA & & & \\
\hline
\end{tabular}

The codes of bank names are explained in Footnote 2 . The symbol " $\theta$ " denotes for three different aggre-

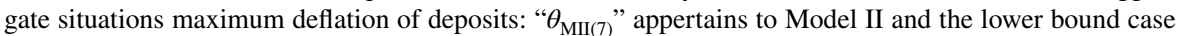
after program (7), " $\theta_{\operatorname{up}(11)}$ " relates to the upper bound case answering to Eq. (11) and " $\theta_{\text {ind(10) }}$ "arises from the model in (10). "NA" signals that the data point was not available or that the value was not computable 
Table 6 Identified inflation factors for corporate loans for banks in the data sample

\begin{tabular}{lllllllllllll}
\hline Bank & 2008 & 2009 & 2010 & 2011 & 2012 & 2013 & 2014 & 2015 & 2016 & $\psi_{\text {MII }(7)}$ & $\psi_{\text {up }(11)}$ & $\psi_{\text {ind(10) }}$ \\
\hline CAC & 2.234 & 1.000 & 1.000 & 1.000 & NA & NA & NA & NA & NA & 1.243 & 1.166 & NA \\
CSOB & 2.608 & 1.421 & 1.561 & 1.393 & 1.750 & 1.977 & NA & NA & NA & 1.724 & 1.142 & NA \\
ING & 2.795 & 1.000 & 1.971 & 1.000 & NA & NA & NA & NA & NA & 1.679 & 1.061 & NA \\
ISTRO & 2.457 & NA & NA & NA & NA & NA & NA & NA & NA & 2.457 & 1.173 & 1.173 \\
KOBA & 4.892 & NA & NA & 1.000 & 1.000 & 1.000 & 1.000 & 1.000 & 1.000 & 1.146 & 1.080 & NA \\
OBER & NA & 1.000 & NA & 2.845 & 3.385 & 3.611 & 1.946 & 1.576 & 1.000 & 2.420 & 1.115 & NA \\
OTP & 2.268 & 2.053 & 2.241 & 2.652 & 2.907 & 2.925 & 3.143 & 2.941 & 2.497 & 2.647 & 1.014 & NA \\
POBA & 4.076 & 3.038 & 2.547 & 1.991 & 1.855 & 1.420 & NA & NA & NA & 2.692 & 1.912 & NA \\
PRIMA & 2.362 & 2.169 & 1.201 & 3.505 & NA & NA & NA & NA & NA & 2.490 & 1.039 & NA \\
SBER & 2.253 & 1.561 & 1.590 & 1.577 & 1.642 & 1.880 & 1.526 & 2.566 & NA & 1.837 & 1.209 & NA \\
SLSP & 2.680 & 1.474 & 1.726 & 1.743 & 1.749 & 1.772 & 1.622 & 1.202 & 1.000 & 1.782 & 1.005 & NA \\
TATRA & 1.402 & 1.072 & 1.014 & 1.000 & 1.013 & 1.011 & 1.000 & 1.000 & 1.000 & 1.029 & 1.064 & NA \\
UNICB & 1.678 & 1.019 & 1.089 & 1.000 & 1.142 & 1.126 & 1.222 & 1.112 & 1.000 & 1.103 & 1.365 & NA \\
VUB & 2.464 & 1.379 & 1.310 & 1.157 & 1.139 & 1.178 & 1.155 & NA & 1.000 & 1.232 & 1.006 & NA \\
$\psi_{\text {lo }}$ & 2.740 & 1.869 & 1.859 & 1.873 & 1.845 & 1.845 & 1.736 & 1.792 & 1.383 & & & \\
$\psi_{\text {up }}$ & 1.256 & 1.163 & 1.161 & 1.097 & 1.072 & 1.026 & 1.004 & 1.003 & 1.000 & & & \\
$\psi_{\text {F }}$ & NA & NA & NA & NA & NA & NA & NA & NA & NA & & & \\
\hline
\end{tabular}

The codes of bank names are explained in Footnote 2. The symbol " $\psi$ " denotes for three different aggregate situations maximum inflation of corporate loans: " $\psi_{\mathrm{MII}(7)}$ " appertains to Model II and the lower bound case after program (7), " $\psi_{\text {up(11) }}$ " relates to the upper bound case answering to Eq. (11) and " $\psi_{\text {ind(10) }}$ " arises from the model in (10). "NA" signals that the data point was not available or that the value was not computable 
Table 7 Identified inflation factors for other loans for banks in the data sample

\begin{tabular}{llllllllllllll}
\hline Bank & 2008 & 2009 & 2010 & 2011 & 2012 & 2013 & 2014 & 2015 & 2016 & $\psi_{\text {MII }(7)}$ & $\psi_{\text {up }(11)}$ & $\psi_{\text {ind(10) }}$ \\
\hline CAC & 2.198 & 1.000 & 1.000 & 1.000 & NA & NA & NA & NA & NA & 1.157 & 1.166 & NA \\
CSOB & 1.676 & 1.339 & 1.200 & 1.043 & 1.007 & 1.000 & NA & NA & NA & 1.141 & 1.142 & NA \\
ING & 1.085 & 1.000 & 1.036 & 1.310 & NA & NA & NA & NA & NA & 1.000 & 1.061 & NA \\
ISTRO & 1.173 & NA & NA & NA & NA & NA & NA & NA & NA & 1.173 & 1.173 & 1.173 \\
KOBA & 2.022 & NA & NA & 1.000 & 1.000 & 1.000 & 1.020 & 1.000 & 1.000 & 1.125 & 1.080 & NA \\
OBER & NA & 1.000 & NA & 2.194 & 1.723 & 1.155 & 1.000 & 1.000 & 1.000 & 1.000 & 1.115 & NA \\
OTP & 1.037 & 1.083 & 1.039 & 1.000 & 1.000 & 1.000 & 1.000 & 1.000 & 1.000 & 1.000 & 1.014 & NA \\
POBA & 2.713 & 3.274 & 3.327 & 1.707 & 1.529 & 1.207 & NA & NA & NA & 2.229 & 1.912 & NA \\
PRIMA & 1.219 & 1.000 & 1.000 & 1.000 & NA & NA & NA & NA & NA & 1.000 & 1.039 & NA \\
SBER & 1.664 & 1.392 & 1.284 & 1.407 & 1.392 & 1.163 & 1.000 & 1.000 & NA & 1.129 & 1.209 & NA \\
SLSP & 1.079 & 1.000 & 1.000 & 1.000 & 1.000 & 1.000 & 1.000 & 1.000 & 1.000 & 1.000 & 1.005 & NA \\
TATRA & 1.259 & 1.187 & 1.165 & 1.105 & 1.008 & 1.000 & 1.000 & 1.000 & 1.000 & 1.014 & 1.064 & NA \\
UNICB & 1.927 & 1.899 & 2.170 & 1.842 & 1.635 & 1.147 & 1.053 & 1.026 & 1.000 & 1.335 & 1.365 & NA \\
VUB & 1.074 & 1.000 & 1.000 & 1.000 & 1.000 & 1.000 & 1.000 & NA & 1.000 & 1.000 & 1.006 & NA \\
$\psi_{\text {lo }}$ & 1.405 & 1.216 & 1.167 & 1.071 & 1.018 & 1.000 & 1.000 & 1.000 & 1.000 & & & \\
$\psi_{\text {up }}$ & 1.256 & 1.163 & 1.161 & 1.097 & 1.072 & 1.026 & 1.004 & 1.003 & 1.000 & & & \\
$\psi_{\text {F }}$ & NA & NA & NA & NA & NA & NA & NA & NA & NA & & & \\
\hline
\end{tabular}

The codes of bank names are explained in Footnote 2. The symbol " $\psi$ " denotes for three different aggregate situations maximum inflation of corporate loans: " $\psi_{\mathrm{MII}(7)}$ " appertains to Model II and the lower bound case after program (7), " $\psi_{\text {up(11) }}$ " relates to the upper bound case answering to Eq. (11) and " $\psi_{\text {ind(10) }}$ " arises from the model in (10). "NA" signals that the data point was not available or that the value was not computable

\section{References}

Ahn H, Le MH (2014) An insight into the specification of the input-output set for DEA-based bank efficiency measurement. Manag Rev Q 64(1):3-37

Banker RD, Morey RC (1986) Efficiency analysis for exogenously fixed inputs and outputs. Oper Res 34(4):513-521

Banker RD, Charnes A, Cooper WW (1984) Some models for estimating technical and scale inefficiencies in data envelopment analysis. Manag Sci 30(9):1078-1092

Banya R, Biekpe N (2018) Banking efficiency and its determinants in selected frontier African markets. Econ Change Restruct 51(1):69-95

Bashir U, Khan S, Jones A, Hussain M (2020) Do banking system transparency and market structure affect financial stability of Chinese banks? Econ Change Restruct. https://doi.org/10.1007/s1064 4-020-09272-x

Bhattacharya S, Thakor AV (1993) Contemporary banking theory. J Financ Intermed 3(1):2-50

Bod'a M (2017) Stochastic sensitivity analysis of concentration measures. CEJOR 25(2):441-471

Bod'a M, Zimková E (2018) Measuring financial intermediation: a model and application to the Slovak banking sector. E a M Ekon Manag 21(3):155-170

Černohorský J (2017) Types of bank loans and their impact on economic development: a case study of the Czech Republic. E\&M Ekon Manag 20(4):34-48

Chiu C-R, Chiu Y-H, Fang C-L, Pang R-Z (2014) The performance of commercial banks based on acontext-dependent range-adjusted measure model. Int Trans Oper Res 21(5):761-775

Choudhry M (2012) The principles of banking. Wiley, Singapore

Cleveland WS (1981) LOWESS: a program for smoothing scatterplots by robust locally weighted regression. Am Stat 35(1):54 
de Guindos L, Schnabel I (2020) The ECB's commercial paper purchases: a targeted response to the economic disturbances caused by COVID-19. The ECB Blog, 3 April 2020. https://www.ecb. europa.eu/press/blog/date/2020/html/ecb.blog200403 54ecc5988b.en.html. Accessed 23 Apr 2020

DiSalvo J, Johnston R (2017). Banking trends: the rise in loan-to-deposit ratios: is 80 the new 60 ? Federal Reserve Bank of Philadelphia, 2017. https://www.philadelphiafed.org/research-and-data/ banking. Accessed 23 Feb 2018

Dutta N, Mukherjee D (2018) Can financial development enhance transparency? Econ Change Restruct 51(3):279-302

Duygun-Fethi M, Pasiouras F (2010) Assessing bank efficiency and performance with operational research and artificial intelligence techniques: a survey. Eur J Oper Res 204(2):189-198

European Banking Authority (2017) Risk assessment report-November 2017. https://www.eba.europ a.eu/documents/10180/2037825/Risk+Assessment+Report+-+November+-2017.pdf. Accessed 1 Apr 2018

European Central Bank (2020) Pandemic emergency purchase programme (PEPP). https://www.ecb. europa.eu/mopo/implement/pepp/html/index.en.html. Accessed 23 Apr 2020

Fortin M, Leclerc A (2007) Should we abandon the intermediation approach for analyzing banking performance? Cahier de recherche/Working Paper 7, 01. Departement d'Economique de l'École de gestion à l'Université de Sherbrooke, 2017. http://gredi.recherche.usherbrooke.ca/wpapers/ GREDI-0701.pdf. Accessed 1 Oct 2018

Freixas X, Rochet JC (2008) Microeconomics of banking, 2nd edn. MIT Press, Cambridge

Heffernan S (2005) Modern banking, 2nd edn. Wiley, Chichester

Ho S-Y, Iyke BN (2018) Finance-growth-poverty nexus: a re-assessment of the trickle-down hypothesis in China. Econ Change Restruct 51(3):221-247

Hondroyiannis G, Lolos S, Papapetrou E (2005) Financial markets and economic growth in Greece, 1986-1999. J Int Financ Mark Inst Money 15(2):173-188

Hong J-D, Jeong K-Y (2019) Combining data envelopment analysis and multi-objective model for the efficient facility location-allocation decision. J Ind Eng Int 15(2):315-331

Lagarde C (2020) Our response to the coronavirus emergency. The ECB Blog, 19 March 2020. https:// www.ecb.europa.eu/press/blog/date/2020/html/ecb.blog200319 11f421e25e.en.html. Accessed 23 Apr 2020

Madura J (2003) Financial markets and institutions, 6th edn. Thomson South-Western, Mason

Malikov E, Kumbhakar SC, Tsionas MG (2015) A cost system approach to the stochastic directional technology distance function with undesirable outputs: the case of US banks in 2001-2010. J Appl Econom 31(7):1407-1429

Matthews K, Thompson J (2005) The economics of banking. Wiley, Chichester

Mitropoulos P, Mitropoulos I (2020) Performance evaluation of retail banking services: Is there a trade-off between production and quality? Manag Decis Econ. https://doi.org/10.1002/mde.3169

Muirhead RJ (1982) Aspects of multivariate statistical theory. Wiley, Hoboken

Office of the Comptroller of the Currency (2016) Prohibition against interstate deposit production. Description: annual host state loan-to-deposit ratios. OCC Bulletin 2016-40. U.S. Department of the Treasury, 2016. https://www.occ.gov/news-issuances/bulletins/2016/bulletin-2016-40.html. Accessed 1 Apr 2018

Olaniyi CO, Oladeji SI (2020) Moderating the effect of institutional quality on the finance-growth nexus: insights from West African countries. Econ Change Restruct. https://doi.org/10.1007/ s10644-020-09275-8

Paradi J, Zhu H (2013) A survey on bank branch efficiency and performance research with data envelopment analysis. Omega 41(1):61-79

Portela MCAS, Thanassoulis E (2005) Profitability of a sample of Portuguese bank branches and its decomposition into technical and allocative components. Eur J Oper Res 162(3):850-866

Portela MCAS, Thanassoulis E (2007) Developing a decomposable measure of profit efficiency using DEA. J Oper Res Soc 58(4):481-490

Saunders A, Cornett MM (2009) Financial markets and institutions, 4th edn. McGraw-Hill/Irwin, New York

Sharma R, Bardhan S (2017) Finance growth nexus across Indian states: evidences from panel cointegration and causality tests. Econom Change Restruct 50(1):1-20

Stone CJ, Hansen M, Kooperber C, Truong YK (1997) The use of polynomial splines and their tensor products in extended linear modeling. Ann Stat 25(4):1371-1470 (with discussion) 
Thanassoulis E, Portela MCS, Despić O (2008) Data envelopment analysis: the mathematical programming approach to efficiency analysis. In: Fried HO, Lovell CAK, Schmidt SS (eds) The measurement of productive efficiency and productivity growth. Oxford University Press, Oxford, pp 251-420

Thiel M (2001) Finance and economic growth-a review of the theory and the available evidence. Directorate general for economic and financial affairs European union: economic paper 158. http://ec.europa.eu/economy_finance/publications/pages/publication884_en.pdf. Accessed 1 Apr 2018

Tone K (2001) A slacks-based measure of efficiency in data envelopment analysis. Eur J Oper Res 130(1):498-509

Venables WN (1974) Algorithm AS 77: Null distribution of the largest root statistic. J R Stat Soc Ser C (Appl Stat) 23(3):458-465

Wilson PW (1993) Detecting outliers in deterministic nonparametric frontier models with multiple outputs. J Bus Econ Stat 11(3):319-323

Publisher's Note Springer Nature remains neutral with regard to jurisdictional claims in published maps and institutional affiliations. 